\title{
Sexual and Place-Based Identity: A Life Course Analysis of LGBTQ+ Undergraduate Understandings of Climate Change in Appalachia
}

\author{
Brandon Anthony Rothrock \\ West Virginia University, bar0044@mix.wvu.edu
}

Follow this and additional works at: https://researchrepository.wvu.edu/etd

Part of the Human Geography Commons, and the Nature and Society Relations Commons

\author{
Recommended Citation \\ Rothrock, Brandon Anthony, "Sexual and Place-Based Identity: A Life Course Analysis of LGBTQ+ \\ Undergraduate Understandings of Climate Change in Appalachia" (2021). Graduate Theses, Dissertations, \\ and Problem Reports. 8327. \\ https://researchrepository.wvu.edu/etd/8327
}

This Thesis is protected by copyright and/or related rights. It has been brought to you by the The Research Repository @ WVU with permission from the rights-holder(s). You are free to use this Thesis in any way that is permitted by the copyright and related rights legislation that applies to your use. For other uses you must obtain permission from the rights-holder(s) directly, unless additional rights are indicated by a Creative Commons license in the record and/ or on the work itself. This Thesis has been accepted for inclusion in WVU Graduate Theses, Dissertations, and Problem Reports collection by an authorized administrator of The Research Repository @ WVU. For more information, please contact researchrepository@mail.wvu.edu. 
Sexual and Place-Based Identity: A Life Course Analysis of LGBTQ+ Undergraduate Understandings of Climate Change in Appalachia

\author{
Brandon Anthony Rothrock
}

Thesis submitted to the Eberly College of Arts and Sciences at West Virginia University for partial fulfillment of the requirements for the degree of Master of Arts in the Department of Geology and Geography

\author{
Martina Angela Caretta, PhD., Chair \\ Cynthia Gorman, $\mathrm{PhD}$. \\ Nicolas Zegre, $\mathrm{PhD}$.
}

Department of Geology and Geography

\title{
Morgantown, West Virginia 2021
}

Key Words: LGBTQ+, environment, identity, feminist geography, queer geography, emotions, Appalachia

Copyright 2021 Brandon Anthony Rothrock 


\begin{abstract}
Sexual and Place-Based Identity: A Life Course Analysis of LGBTQ+ Undergraduate Understandings of Climate Change in Appalachia
\end{abstract}

\author{
Brandon Anthony Rothrock
}

LGBTQ+ persons face heightened vulnerability to climate change-induced disasters due to their sexual orientation, gender identity, and gender expression. Yet, there are limited studies that examine how LGBTQ+ students, particularly in a higher-education setting, understand climate change in relation to their sexuality. With a majority of studies on LGBTQ+ persons and climate change focusing on LGBTQ+ experience during and after disaster, there is a gap in understanding LGBTQ+ perceptions of climate change in the day-to-day. Particularly in Appalachia, a region characterized by a strong place-attachment to and a collective identity with the natural environment, studies of marginalized groups' perceptions of climate change are lacking.

This thesis utilizes a case study of LGBTQ+ undergraduate college students at large, public institutions in Appalachia. Based on semi-structured interviews and focus groups, this thesis investigates the ways in which sexual and place-based identity influence LGBTQ+ undergraduate understandings of the environment and climate change.

LGBTQ+ undergraduate students spoke to the unique intersection of Appalachian identity and queer identity, and how this intersection influences their understandings of the environment. As students transition from home to the college space, their understandings of their own sexual and gender identities, as well as of climate change, are further cultivated. Participants also spoke to the privilege that whiteness and class have during present and future climate change impacts, and how such privileges intersect with their queer identity. As they are constantly bombarded by information on a myriad of social and environmental topics in their coursework, the participants understand that climate change is occurring. Yet, they do not understand localized climate change impacts in Appalachia, prompting them to be uncertain about the future, their identities, and climate change.

This thesis has broad implications for studies of climate change across the sub-disciplines of feminist, queer, and emotional geography. As there are limited studies on climate change perceptions at the higher education level, and almost no studies in Appalachia specifically, this thesis explores the intersections of identity, emotions, and perceptions. 
Table of Contents

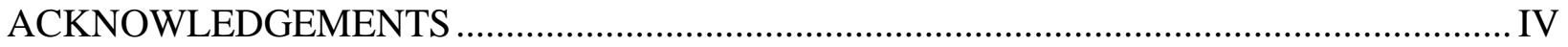

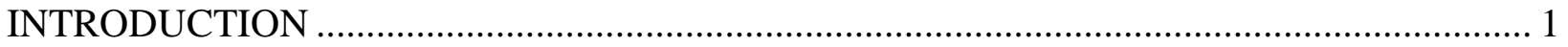

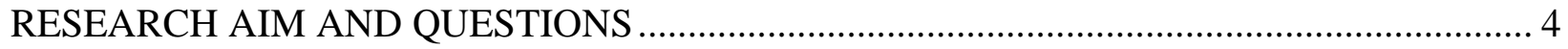

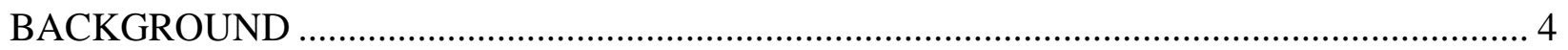

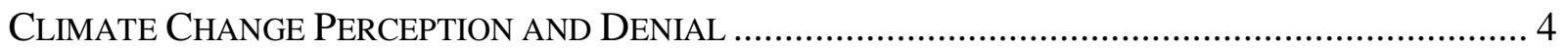

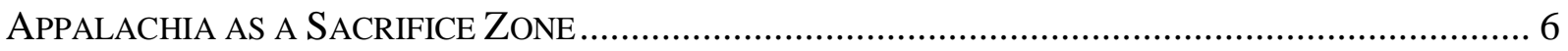

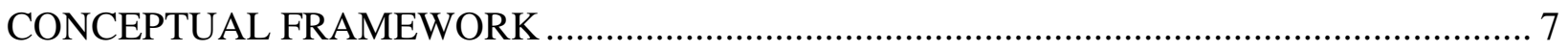

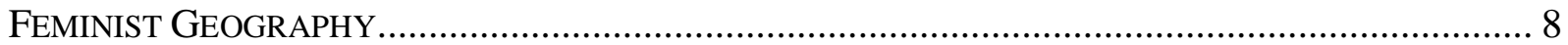

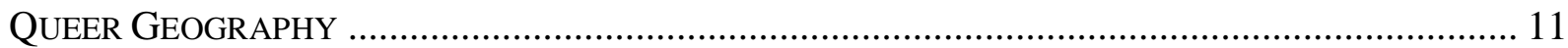

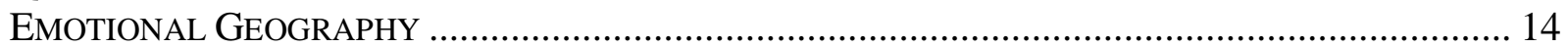

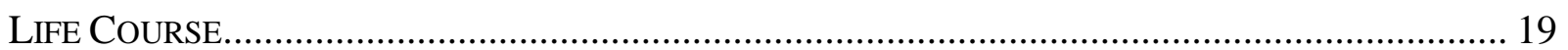

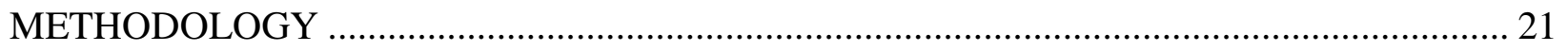

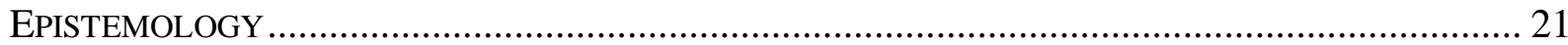

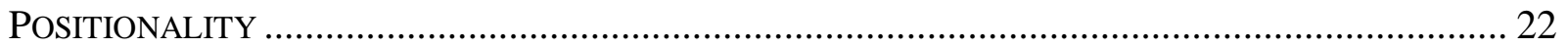

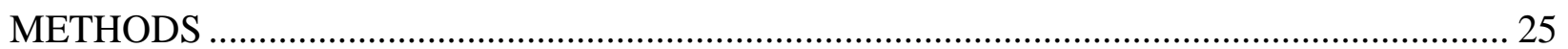

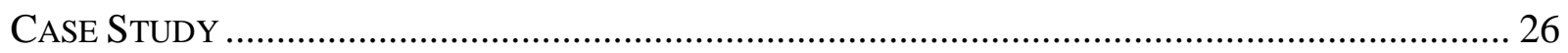

SURVEY ....

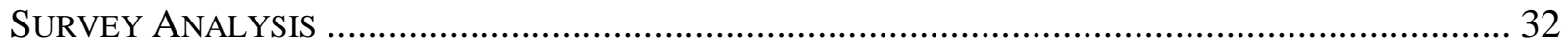

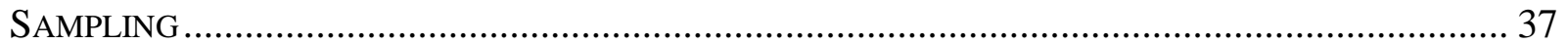

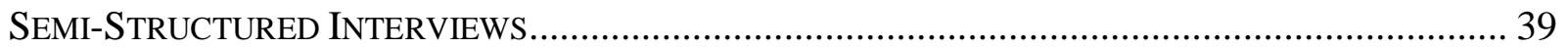

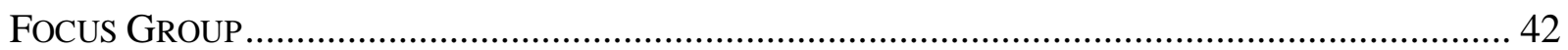

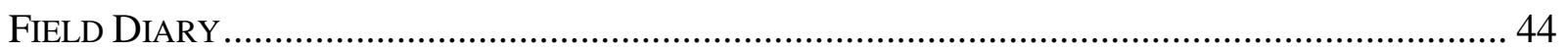

VALIDATION AND MEMBER CHECKING........................................................................... 44

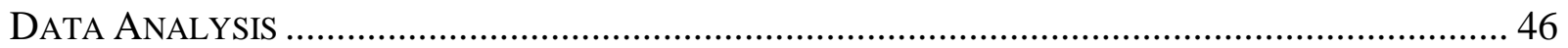

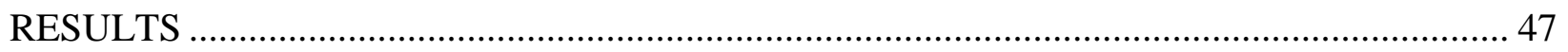

Before College: SeXual IdENTITY Formation In APPALACHIA........................................... 49

During College: Changing Understanding OF THE ENVIRONMENT AND Climate CHANGE

After College: Climate Change AND the Future ......................................................... 57

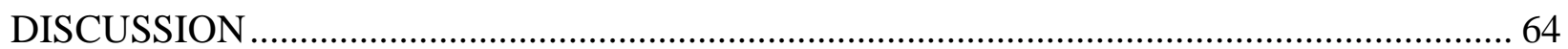

SEXUAL AND Place-BASEd IDENTITIES AND THEIR INFLUENCE ON UNDERSTANDINGS OF THE

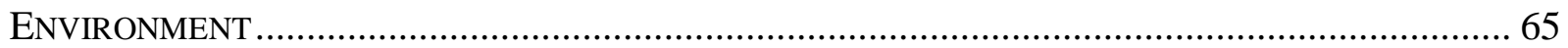

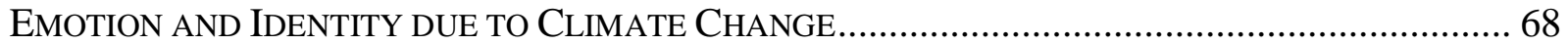

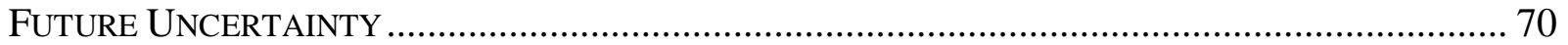

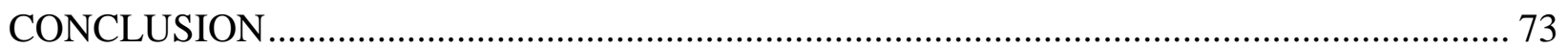




\section{Acknowledgements}

I would first like to thank everyone who participated in my research, from West Virginia to North Carolina, for sharing a piece of their story with me. I cannot thank you all enough for opening your hearts and your minds to my research while providing me with insight and selfreflection of my own journey in academia and the world at-large as a queer person. I would also like to thank those who have supported me on my journey through graduate school. To my advisor and committee chair, Dr. Martina Angela Caretta, thank you for believing in me and my work and making me a better writer. I am thankful for your continued commitment to making me succeed in anything (and everything) I had applied for or put my mind towards. Even thousands of miles away you still put effort into me, and for that I am thankful. I am also thankful to my committee members, Dr. Nico Zegre and Dr. Cynthia Gorman, for their expertise in their respective fields and for elevating my thoughts throughout this thesis. I am happy to have taken courses with both of you during my time at West Virginia University. To my graduate advisor and fellow Penn State alum, Dr. Jamie Shinn, thank you for taking me under your wing this past year and teaching me through your research projects. I have learned an immense amount of new skills from you that will stay with me well into the future. I'd also like to thank colleagues who embarked on this crazy little thing we call 'graduate school' with me. To Elizabeth Dever, thank you for mentoring me through my first year of graduate school and being my lab mate. I couldn't have completed this degree without your guidance, suggestions, and wisdom. To Rachael Hood, thank you for being a constant friend to lean on when graduate work got difficult or messy. I could not have made it through this past year without your help and support. To Emily Tingler, Valerie Slone, and Valentina Muraleedharan, thank you all for your constant laughter and banter. We made it through countless courses together with just the four of us, and I am thankful for all of you to bounce ideas off of, whether it be academic projects or life problems. And lastly, I'd like to thank the Department of Geology and Geography at West Virginia University for their constant support throughout my graduate experience, not only for funding my education, but for every student, professor, and staff who made this experience possible. 


\section{Introduction}

"In the early morning of August 29"th 2005, Hurricane Katrina battered the coastal shores of Louisiana, Mississippi, and Alabama. The Category 4 hurricane brought extreme flooding, resulting in the failure of New Orleans' aging levee system. Torrential downpours, combined with the inundation of the city's two rivers, led to $80 \%$ of New Orleans being underwater. Local agencies tasked with providing aid and community support were immobilized, prompting widespread chaos as residents struggled to find adequate food, shelter, and clean water. Many of the tens of thousands of residents that stayed behind huddled in shelters such as the Mercedes Superdome, where tensions ran high, supplies ran low, and the threat of waterborne bacteria became an increasing concern. Others chose to evacuate and seek shelter in the surrounding inland areas of Louisiana, creating massive traffic jams that left evacuees stranded on the interstate.

Arpollo Vicks, a male-to-female transgender person, started living her life as a woman in New Orleans when she was twenty years old. Her friends and family called her Sharli'e, and the students that she worked with as a substitute teacher called her Ms. Vicks. Sharli'e's life was turned upside down by Hurricane Katrina, as she and her friends swam and treaded over a mile and a half to reach the New Orleans Convention Center, another makeshift shelter similar to the Mercedes Superdome. They spent two nights in the Convention Center but decided to leave after the threat of gun violence and disease. They then spent two days stranded under an Interstate 10 overpass until they were picked up by a rescue bus bound for Houston, Texas. Arriving at Texas A\&M University's Reed Arena, she and her two friends were hungry and in desperate need of a shower.

Sharli'e explained her situation to a volunteer, citing her fear of showering in the men's bathroom. The volunteer felt it was appropriate for Sharli'e to shower in the women's bathroom and allowed her to do so. The next day as Sharli'e exited the women's bathroom, she was immediately arrested by the police for criminal trespassing. Her bail was set at $\$ 6,000$, an exorbitant fee for a criminal trespassing charge; she was left in jail for almost five days, all for showering in a women's restroom" (Rothrock, 2020).

The above vignette that I wrote for The Rachel Carson Council based on a news story in The Houston Chronicle following the aftermath of Hurricane Katrina (Gray, 2011) characterizes the intersections of LGBTQ+ vulnerability in the everyday and the extreme impacts of climate change. It is well known that climate change is expected to create differentiated vulnerability and insecurity across social strata and named identity categories such as race, gender, class, and sexuality (Sultana, 2014; Denton, 2002; Nelson et al., 2002). The gendered implications of 
climate change in particular will place people in different positions regarding their ability to respond to and cope with socioecological and environmental changes (Sultana, 2014). Specifically, LGBTQ+ people face heightened vulnerability during disasters because of their sexual orientation, gender identity, and gender expression (Gorman-Murray et al., 2017; Yamashita et al., 2017). Fear of discrimination and lack of access to resources during disaster may be symptomatic of perceived vulnerabilities LGBTQ+ people face in everyday life.

As an example, in the aftermath of the 2011 earthquake in Japan, a mobile hotline with multiple options for varying guidance and assistance was established for residents in areas most affected. Those who suffered difficulties in the aftermath in relation to their sexual orientation, gender identity and/or gender expression were expected to press a hotline option that differed from the main emergency hotline. Out of the approximately 11 million calls logged by the hotline, only $3.6 \%$ of hotline users selected the sexual orientation, gender identity and/or gender expression option, which was a significantly smaller number of documented calls expected in the area (Yamashita et al., 2017). Hotline operators in the area expected between 1-2 million of the 11 million calls to be logged to this specific hotline option, given the estimate that over $10 \%$ of the general population in the area identifies as LGBTQ+. This example furthers the notion that there is perceived insecurity associated with, and fewer societal protections for, LGBTQ+ persons. Vulnerability, therefore, differentiates across identity as well (Gorman-Murray et al., 2017).

Sexual identity formation oftentimes occurs for individuals in college, as the environment provides opportunity for people with diverse backgrounds, including those who identify as gender and sexual minorities, to interact with and learn from differing perspectives and those with similar queer experiences (Hughes and Hurtado, 2018; Hurtado et al., 2012). LGBTQ+ student organizations and clubs also help to provide inclusive spaces for those questioning their sexuality, especially for those who come from non-accepting or homophobic households (Hughes, 2018). Apart from sexual identity formation, students in higher education are also bombarded with an array of information on a myriad of topics, with discussions of climate change often at the forefront of discussions in various STEM-related courses (Leichenko and O'Brien, 2020). These two intersecting learning processes of sexual identity formation and climate change in the college space spur conversations of privilege, uncertainty, and 
environmental impacts. This thesis explores how college-aged, LGBTQ+ students understand their sexuality in relation to their understandings of the environment and climate change.

The following research fills gaps in academic, geographic literature in the context of climate change and LGBTQ+ experience. Much research has been published at the intersection of LGBTQ+ experience and climate change disaster vulnerability (Goldsmith et al., forthcoming; Tierney, 2019; Gorman-Murray et al., 2017; Wisner et al., 2017; Dominey-Howes et al., 2014; Stukes, 2014; D’Ooge, 2008). Yet, no geographic studies utilize place-based attachment and emotions to frame LGBTQ+ experience and understandings of the environment and climate change. Further, few geographic studies outside of youth geographies (Worth, 2009) and political geography (Gecas, 2003) utilize the concept of life course as an approach to data analysis, leaving its utilization in work on gender and sexuality sparse (Wimark, 2020).

To the best of my knowledge, there is no academic research being conducted in the United States, and more specifically Appalachia, that focuses on LGBTQ+ undergraduate students' understandings of climate change. This emphasis aids policy and decision-making regarding climate change mitigation and adaptation strategies that attempt to reduce vulnerability across scale, given LGBTQ+ perceptions, opinions, and beliefs are often unaccounted for. Likewise, placed-based attachment and identity formation are often overlooked in natural resource management or other state policy on climate change, which minimizes and shifts the ability for humans to effectively respond to change within their immediate environment (Galway, 2018; Schoenefeld, 2015; Devine-Wright, 2012; Willox et al., 2012). With college-aged students being the country's youngest voters and future leaders, this study and its analysis of place-based attachment, sexual identity, and perceived risk of LGBTQ+ college students will provide more holistic analyses of climate change necessary to support present and future policy debates. Understanding how marginalized individuals understand climate change is crucial in present and future framings of the issue in a way that is more digestible and accessible to the general American public, for studies highlighting individual vulnerabilities in the everyday may produce broader empathy. Not to mention, dialogue across disparate academic concepts aids future productions of interdisciplinary research. Such dialogue is necessary to fill lack of conceptual and empirical 'bridge-building' between academic disciplines (Wright, 2008). 
The thesis is organized in the following manner. First, the research aim and questions are identified, followed by a background section on climate change perception and denial in Appalachia. The background section helps to inform the various systems and structures in the United States which produce regionalized perceptions and opinions of climate change. Then, a conceptual framework outlines the different concepts in the sub-disciplines of feminist geography, queer geography, and emotional geography that are utilized to frame the research. Further, the concept of life course is explained as a basis of data analysis. Following the conceptual framework, research methodologies are outlined and thesis results are explained. Following the results, a discussion involving available literature, findings, and future research avenues ensues.

\section{Research Aim and Questions}

The aim of this research is to explore LGBTQ+ student understandings of the environment and climate change in Appalachia and how their sexual and place-based identities influence these understandings. Further, the aim is to explore the emotions tied to these understandings as well as understandings of future climate change impacts. This aim has been fulfilled by investigating the following research questions:

1. How do sexual and place-based identities influence LGBTQ+ understandings of the environment?

2. How do these identities manifest in their emotions and perceptions of climate change?

3. How do perceptions of climate change affect their future plans?

\section{Background}

In the following section, I provide background information on discussions of climate change and climate denialism in the U.S. as well as detail the extractive and collective history of Appalachia.

\section{Climate Change Perception and Denial}

Despite consensus among scientists that human activity, such as the burning of fossil fuels, is the main driver of anthropogenic climate change (Allen et al., 2018), there is a disconnect in 
consensus among the general public in the United States (Bolsen and Druckman, 2018). Conservative media outlets such as Fox News, in conjunction with major oil and gas company lobbying efforts, divide public opinion, perceptions, and beliefs (Grasso, 2019; Bolsen and Shapiro, 2017; Bolsen et al., 2015; Hmielowski et al., 2013). Conspiracy theories and conservative ideologies often produce climate skepticism, as the United States is one of the only countries where such stark political ideological divides on climate change occur (Hornsey et al., 2018). Perceptions of climate change are also influenced by identity categories such as race and gender alongside political affiliation. White, conservative males are more likely than other adults in the United States to endorse climate denial (McCright and Dunlap, 2011), and perceive risk to environmental change less than gender and racial minorities (Flynn et al., 1994).

Climate denial is an attempt by men in power, who are most oftentimes white, heterosexual males with stake in high polluting industries such as oil and gas, to create perceived conflict on climate change science across broader society (Lahsen, 2005; Gelbspan, 2004; Leggett, 2001; Rampton and Stauber, 2001). Such individuals fund special interest lobbying groups and thinktanks, such as the Heartland Institute, which help to escalate climate skepticism and further exploit U.S. media companies into creating an acceptance-denial divide on the issue (Anshelm and Hultman, 2013). These groups which produce widespread denialism act as identityprotective cognition for conservatives in the U.S. at-large (McCright and Dunlap, 2011), further stalling climate action on the national scale.

Climate skepticism and the politicization of climate change has direct connotations to climate literacy amongst the American public. According to Climate Opinion Maps by the Yale Program on Climate Change Communication (YPCCC), states in the Appalachian region often have below-average climate change perceptions in relation to the rest of the country. In the most recent data collected by the YPCCC in 2020, it is estimated that $72 \%$ of adults in the U.S. believe that global warming is happening in comparison to only $59 \%$ of adults in West Virginia and only $62 \%$ of adults in Kentucky (Howe et al., 2015). The percentages across a myriad of survey questions utilized for the Climate Opinion Maps show that West Virginia, a state at the heart of the Appalachian region, often has the lowest adult perceptions and beliefs in the country. 


\section{Appalachia as a Sacrifice Zone}

The United States is considered by the United Nations as a highly developed nation with the economic and social capacity to respond to and mitigate the physical and structural effects of climate change (Allen et al., 2018). However, there are high disparities in such capacities across regions. The Appalachian region has suffered decades of socio-economic and environmental deterioration at the hands of the extractive industry (Fabricant, 2015). Coal mining activities over the past two centuries have shaped the region's rural landscape into a sacrifice zone (Gaventa, 2019). With coal-related extraction activities such as mountaintop removal decimating the natural landscape (Lewin, 2019), extraction development has turned the region into an industrial site comprised of roads, pipelines, and processing facilities (Eller, 2008). This development has effectively left Appalachians dependent on the industry for employment and livelihood.

The overall decline of the U.S. coal industry over the past few decades, however, has also produced negative, cascading effects in the form of poverty, widespread unemployment, and community deterioration (Fabricant, 2015). With many Appalachian communities' economic identities tied directly to the coal industry, these identities are utilized by the extractive industry to maintain political influence region-wide and to shirk responsibilities associated with environmental clean-up activities (Bell and York, 2010). Despite such negative socio-economic and environmental changes, the positive discourse surrounding coal heritage remains. This heritage produces anti-environmental sentiments among Appalachians who feel that national environmental policies are directed towards them and negatively impact their livelihood (Lewin, 2019). These sentiments further uphold the very extractive industries which have produced longterm issues with the environment, public health, and economic status of rural communities (Chalfant and Corrigan, 2019). As a result, younger individuals in the region attempt to leave it for better opportunity, directly contributing to unfettered brain drain (Vazzana and RudiPolloshka, 2019).

These declines and ruptures in community stability not only leave the population physically vulnerable to climate-induced impacts such as flooding events (Shinn and Caretta, 2020), but also leave individuals emotionally vulnerable and unable to cope with changes in their environment. Climate change stands to worsen mental health (Obradovich et al., 2018; 
McMichael et al., 2015) and alter place-based attachment (Scannell and Gifford, 2010). Given the unique, collective identity of Appalachia, which is often derived from a historical, strong place-based attachment to the natural environment (Barcus and Brunn, 2010), climate change impacts directly threaten identity formations.

\section{Conceptual Framework}

I situate this research within the three sub-disciplines of feminist geography, queer geography, and emotional geography. These three sub-disciplines are utilized to study the broader research area of climate change. The below figure [Figure 1] illustrates the different concepts located within my research and highlights the research gap that I aim to contribute to.

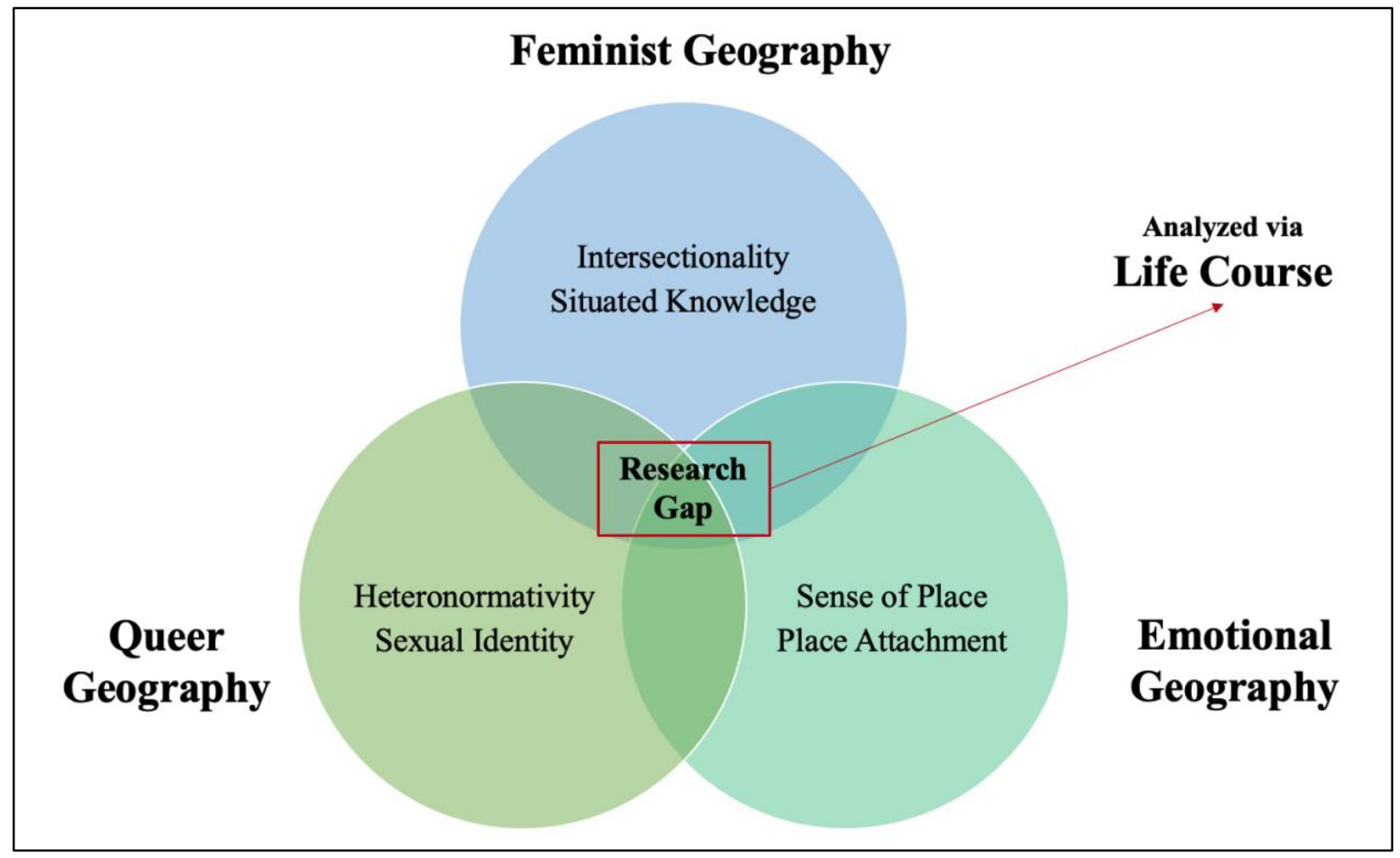

Figure 1: Conceptual framework comprised of three sub-disciplines: feminist geography, queer geography, and emotional geography. Each overlap with one another, yet there are gaps particularly at the confluence of studies on LGBTQ+ sexual identity and place-based identity. The main research gap is addressed utilizing the concept of life course as an analytical tool.

Within the sub-discipline of feminist geography, the concepts of situated knowledges and intersectionality help contextualize the identity of research participants. Within the sub-discipline 
of queer geography, the concepts of heteronormativity and queer space help contextualize the space of Appalachia and how queer identity interacts with dominant societal discourses in the region. Within the sub-discipline of emotional geography, the concepts of sense of place and place attachment help contextualize the way in which LGBTQ+ undergraduate students understand their local environment and climate change impacts. An examination of LGBTQ+ student emotions and perceptions span across the sub-disciplines of emotional geography and queer geography, while topics from both feminist geography and queer geography intersect and aid explaining the lived experience of LGBTQ+ persons. Feminist geography and emotional geography also overlap one another via concepts involving bodies in space and place attachment.

Each of the sub-disciplines and their associated, overlapping concepts provide critical connections to understanding the sexual and place-based identities of LGBTQ+ undergraduate students. These identities and understandings are then further analyzed in the context of climate change.

Though there are significant overlaps between the three sub-disciplines, there are also numerous gaps within existing literature on climate change within geography. For example, research linking climate change and queer geography most often focuses on disaster vulnerability (Gorman-Murray et al., 2017; Wisner et al., 2017; Dominey-Howes et al., 2014; Stukes, 2014; D’Ooge, 2008), while my research aims to address how queer individuals are thinking about concepts of climate change outside of the context of disaster. In tandem, studies of emotions, place-based attachment and identity in the context of climate change are often housed in other disciplines such as sociology or psychology (Scannell and Gifford, 2010; Diener and Hagen, 2020; Cunsolo and Ellis, 2018). Further, I utilize the concept of life course as an analytical tool for my results (Gecas, 2003). The results then speak to the research gap at the intersection of feminist, queer, and emotional geography.

\section{Feminist Geography}

Feminist geography stems from critiques of the discipline being traditionally dominated by white men. Up into the late 1970s, it was commonplace for the use of the term 'man' to encompass all of humanity in geographic research and academia more broadly. Since almost all positions of power within the discipline were male-dominated, men had the ability to control who or what 
was relevant in geographical thought (Rose, 1993). Research in academia was structured and executed solely at the discretion of men's experiences, values, or goals; therefore, the problems and concerns of women were grossly neglected. Knowledge created by women was often deemed too 'unscientific,' 'subjective,' or 'personal' to qualify as knowledge, and women were sanctioned by various male-dominated institutions such as the Royal Geographical Society (Domosh, 1991). Making Truth context free is in line with the idea that man is separate from nature and that 'true' science must be objective (Longhurst, 1995).

Constructed dualisms such as mind and body, sex and gender, and essentialism and constructionism reproduce masculinist, objective knowledge that attempts to be Truth. Mind and body were therefore theorized as acting in opposition to one another rather than being two parts of the same being (Rose, 1993). The mind is labeled as objective and corelated with masculinity, while the body has been labeled as subjective and correlated with femininity (Longhurst, 1995). This gendering of knowledge removes both the power and agency associated with the knowing, human subject. The concept of situated knowledge aims to reject objective ideals and positivistic biases, as the production of objective knowledge is shaped by identity categories such as race, gender, and class. Donna Haraway (1988) asserts that situated knowledges promise more accurate and richer accounts of the world; by learning from individual, partial perspectives, these partial perspectives can coalesce and produce an objective vision (Haraway, 1988: 415). Treating knowledge production as subjective and stemming from the body produces an embodied feminist objectivity. Knowledge production is therefore altered by the positionality of the researcher; the acknowledgement of one's subjectivity increases the objectivity of the research. When researching marginalized populations for example, raising the voices of the marginalized produces more objectivity because Truth becomes closer to being attained.

Masculinist, objective knowledge also has the power to construct a white, heterosexual male 'master subject' in geographic research, which leads to the production of the 'Other'. Feminist scholars more broadly have focused on the dichotomy of difference between men and women as the basis for theorization (Hawkesworth, 2006). They argue that men and women shared essential characteristics which made women equal to men via a common human identity. However, these academic pursuits have been widely critiqued for only focusing on women's 
oppression and gender difference, therefore ignoring the deconstruction of other social hierarchies such as race or class (Knopp, 2007). By being race-blind, this scholarship has historically only largely focused on and addressed the concerns of white women feminists. Critical work by Black feminists such as Crenshaw (1989) and Walker (1979) document the lived experience of Black women, attempting to widen feminist research to encompass all women. Feminist theory often becomes devalued to Black women due to its evolution from a white, racial context. This context further excludes women of color, particularly "when white women speak for and as women" (Crenshaw, 1989: 154). Crenshaw (1989) coined the term intersectionality to highlight the unique intersection of discrimination Black women experience, in the sense that their positionality can be both similar and different to the legal discrimination experienced by white women and Black men (p. 149). Intersectionality is defined as an intersection of identity markers, such as gender and race, in which overlapping systems of discrimination or disadvantage are produced. Due to their intersectional identity as women and people of color, women of color are frequently marginalized or discriminated against within both identities (Crenshaw, 1989).

However, intersectionality as a concept should not take on an additive approach (Hopkins, 2007; Yuval-Davis, 2006). Yuval-Davis (2006) asserts that there is no such thing as suffering from oppression 'as Black' and 'as a woman'. Simply adding the two identity categories to one another does not produce a compounding identity (Yuval-Davis, 2006: 195). Rather, intersectionality asserts that the two identities are a part of an overarching oppression that does not divide one's social standing. Race and gender in particular should not be viewed as separate social, identity categories because their separation can lead to further marginalization of women of color. Other feminists such as Puar (2011) have asserted that the concept of intersectionality should not 'travel' to other disciplines outside of Black feminist thought and legal studies, for identity categories can be reified through its conceptualization outside of its original context. Intersectionality as a method has been predominantly used to quantify the unique difference that women of color experience, most often demarcating women of color as the 'Other' (Puar, 2011). The 'Other', as Puar (2011) asserts, is produced via a focus on difference. Identity categories such as race, gender, and class can become universalized and embedded in Western feminist 
thought; these categories further naturalize positionality and produce essentialist assumptions of the 'Other' who is oftentimes a woman of color.

Feminist geographers must acknowledge the history of intersectionality and further avoid the misuse of the concept within the sub-discipline (Hopkins, 2017). Ignoring the origins of intersectionality stands to problematically reinforce geography as a white and racist discipline.

Feminist geographers often apply the concept of intersectionality to geographical concepts of space and place. Valentine (2007) analyzes intersectionality through what she calls 'geometries of oppression,' in which power dynamics of social identity categories can shift and change throughout space and time. Binaries such as heterosexual / homosexual and man / woman can act as oppressive to those whose identities do fall outside of them. Feminist geography, as Valentine (2007) asserts, stands to advance the theorization of intersectionality via the significance of space, and how space and place play a direct role in subject and identity formation at-large. By utilizing the concept of intersectionality to focus on how power infiltrates space, geographers stand to make key methodological and theoretical contributions to research addressing social inequity.

\section{Queer Geography}

Queer theory stems from the rapid development of lesbian and gay studies in academic research and the queer activism associated with the organization Queer Nation in the 1990s (Cohen, 2005). Queer theory and queer politics more broadly emerge from feminist theory and politics as well (Walters, 1996). As feminism and gender had become more widely theorized by academic scholars by the 1990s, budding developments in queer theory and practice began to emerge. The term queer was utilized as a means of 'going against' the gender-specific terms of gay and lesbian, and in certain instances had the power to produce new markers of sexual identity and sexual expression outside of gender. However, the term has become synonymous with gay and lesbian in mainstream culture due to uneven power dynamics (Walters, 1996). Queer can act as an agent for destabilizing the heterosexual / homosexual binary, but based on geometries of oppression (Valentine, 2007), the term can reinforce the binary in certain instances. By constructing queer in opposition to heterosexual, queer activists have invoked a singleoppression framework in which the radical potential and power of queer politics has been 
minimized (Cohen, 2005: 44). By only focusing on one characteristic of identity, in this case sexuality, queer activists misrepresent power structures and reject overlapping intersections of power that dictate queer livelihoods. For example, Cohen (2005) comments on the multiple identities that locate her and other queer people of color at the margins of not only the LGBTQ+ community, but of society at-large. Focusing solely on differences between identity categories only stands to stabilize and naturalize their use further, and power embedded within identity categories continues to minimize the potential of queer transcendence (Cohen, 2005: 34).

Gender theorists such as Judith Butler (1993) stand to deconstruct gender and sexual identities outside the binaries of heterosexual / homosexual and man / woman through an analysis of performativity and an examination of queer people in space. Butler (1993) comments on the construction of the identity category of 'lesbian', and how this category adheres to a particular power and status of heteronormativity. Both being a lesbian and striving to be a lesbian have an attached performativity; the act of being a lesbian is constantly repeated over and over through different performances, and this repetition, instead of strengthening or giving power to the identity category, makes the category unstable in space, given its need to incessantly reaffirm its power and status (Butler, 1993: 21). Butler (1993) asserts that heterosexual identities are also performed as imitation, yet through uneven power dynamics these identities are viewed as the origin of all other identity. She furthers her argument by asserting that the binary of heterosexual / homosexual is unstable, and categories of sex, sexual identity, and gender are merely effects of performing a heterosexual 'origin' of all sex.

Queer geographers add complication to the heterosexual / homosexual binary debates in queer theory via the concepts of space and place. Gorman-Murray (2006) focuses on the lived experience of gay men and lesbians through the home as a space and site of identity construction, and how these lived experiences are shrouded in heteronormativity. The identities of gay men and lesbians are often inhibited in the everyday use of public and private spaces; social norms, housing design, and government policies have often hetero-sexualized the home, as the home is often considered "the primary site of heterosexual reproduction and heteronormative socialization" (Gorman-Murray, 2006: 147). Gay and lesbian couples often use their homes to 
establish and re-write their partnerships as homosexual through home-making processes such as creating shared spaces or accumulating household objects together (Gorman-Murray, 2006).

Other queer geographic research by Oswin (2008) showcases gay experience outside the home. Her research finds that gay men experience urban neighborhoods differently than heterosexual men based on sexuality but also on the normative heterosexual spaces of cities. Yet, space is not naturalized as heterosexual but rather produced as such (Binnie, 1997a: 223 in Oswin, 2008). Though spaces designated as queer allow for the formation of sexual identity, as witnessed in Misgav and Johnston's (2014) work on a queer nightclub in Tel Aviv, they can also act as exclusionary spaces for individuals that fit outside gay and lesbian identities. Not fitting into the dichotomy of gay and lesbian, the identities of the Coccinelles [trans-women] were effectively suppressed within the nightclub, as there was a clear spatial divide between the Coccinelles and the gay men; they occupied the secondary, smaller hall to socialize while the gay men occupied the main, larger hall to dance. However, the secondary hall acted as a catalyst for the Coccinelles to showcase their femininity and identity, as they spent countless hours dressing up to boost their own confidence and to pass as feminine. To add further bodily component, the Coccinelles aimed to move within the smaller hall as little as possible to avoid sweating and ruining their makeup and outfits, while the gay men of the other hall took their shirts off and sweated as they pleased.

This performance of masculinity and femininity in space again adds to Butler's argument that queers constantly resist the origin of heterosexuality in society, yet gender norms i.e. acting feminine or masculine to fulfill a certain purpose or role, are essentially ingrained in spaces. Transgender people act as a counter to this masculine / feminine binary and aid Valentine's (2007) assertion that identity is fluid and ebbs and flows in context. What we choose to do (or not) with our bodies and our sexuality in space produce more and more 'closets' or sets of challenges (Brown, 2000). And yet, these challenges from the closet and from the margins of society (hooks, 1990) have a certain power to them. The power of norms is evident in queer spaces, as norms can either empower or strip power of individuals. A queer perspective further complicates normative binaries of women and men, for the individual has the power (or not) to create their own identities in space. 
Power dynamics behind sexuality and heteronormativity in space are also evident in recent studies on the vulnerability of sexual and gender minorities in the face of disaster (GormanMurray et al., 2017; Stukes, 2014; D’Ooge, 2008). Sexual and gender minorities are often the most severely affected by disasters, such as hurricanes, due to lack of accessible protections (Gaillard et al., 2017). Likewise, their marginalized position in the everyday places them at a higher risk when confronted with disaster. Everyday vulnerability is reinforced by lack of specific policies addressing the needs of marginalized populations (Gaillard et al., 2017; D’Ooge, 2008). For instance, a trans evacuee from New Orleans in the aftermath of Hurricane Katrina was arrested and detained after taking a shower in a women's bathroom in the shelter she was staying in (Rothrock, 2020; Gray, 2011; D’Ooge, 2008); this example further questions the fate of those who do not identify within heterosexual norms or within a male/female binary in disaster situations (Gaillard et al., 2017).

\section{Emotional Geography}

Following the quantitative revolution and dominance of spatial science within the discipline of geography, human geographers such as Yi-Fu Tuan, David Ley, Edward Ralph, Anne Buttimer, and David Seamon all shared a desire to re-place humans at the center of geographical thought. In the 1970s, human geographers engaged with topics of place attachment through their focus on the concept of sense of place (Pretty et al., 2003; Lewis, 1979; Tuan, 1979; Relph, 1976). Sense of place refers to the direct and complex experience of humans over a period of time and within a particular space or context (Relph, 1976). There are subjective meanings, whether individual or community-based, that humans attach to particular places (Cresswell, 2014). Tuan (1979) was one of the first geographers to explore the multi-dimensionality of place through its ties to the body, the mind, and the spirit and across micro- and macro-scales. Through a focus on the home, Tuan (1979) asserted that the home is an embodiment of care. Human ties to home are made strong through blood, such as relatives and parents, or by physical proximity to a distinct location, such as a city or town; these ties are often associated with particular emotions. The multi-dimensionality of place soon became a central tenant of the sub-discipline of human geography and can be further utilized within growing literature in human dimensions of climate change research. 
Place-based attachment, a concept similar to sense of place, is defined as a level of attachment, whether emotional or physical or both, that an individual or a collective has with a particular place (Willox et al., 2012). Place-based attachment shapes place-based identity, which is defined as the creation of individual identities through or within a connection to place (Scannell and Gifford, 2012; Willox et al., 2012). Since the 70s, there has been varied epistemological, methodological, and theoretical frameworks that characterize place attachment research in the discipline of geography (Diener and Hagen, 2020). Due to this variety however, Diener and Hagen (2020) assert that place attachment research in geography may be too broad and can potentially dilute the concept's theoretical power (p. 3). Yet, the concept of place attachment, although not always conceptualized directly, has been taken up by geographers who study a wide range of topics, from geographical belonging (hooks, 1991) to home (Domosh and Seager, 2001). Place attachment has been widely utilized and theorized outside of geography in other disciplines such as psychology and sociology. Scannell and Gifford's (2010) popular threedimensional framework helps to conceptualize place attachment through the person, the psychological, and the place. Their model of place attachment research [Figure 2] is useful in understanding the multi-faceted aspects of place attachment and helps to simplify and organize person-place bonding.

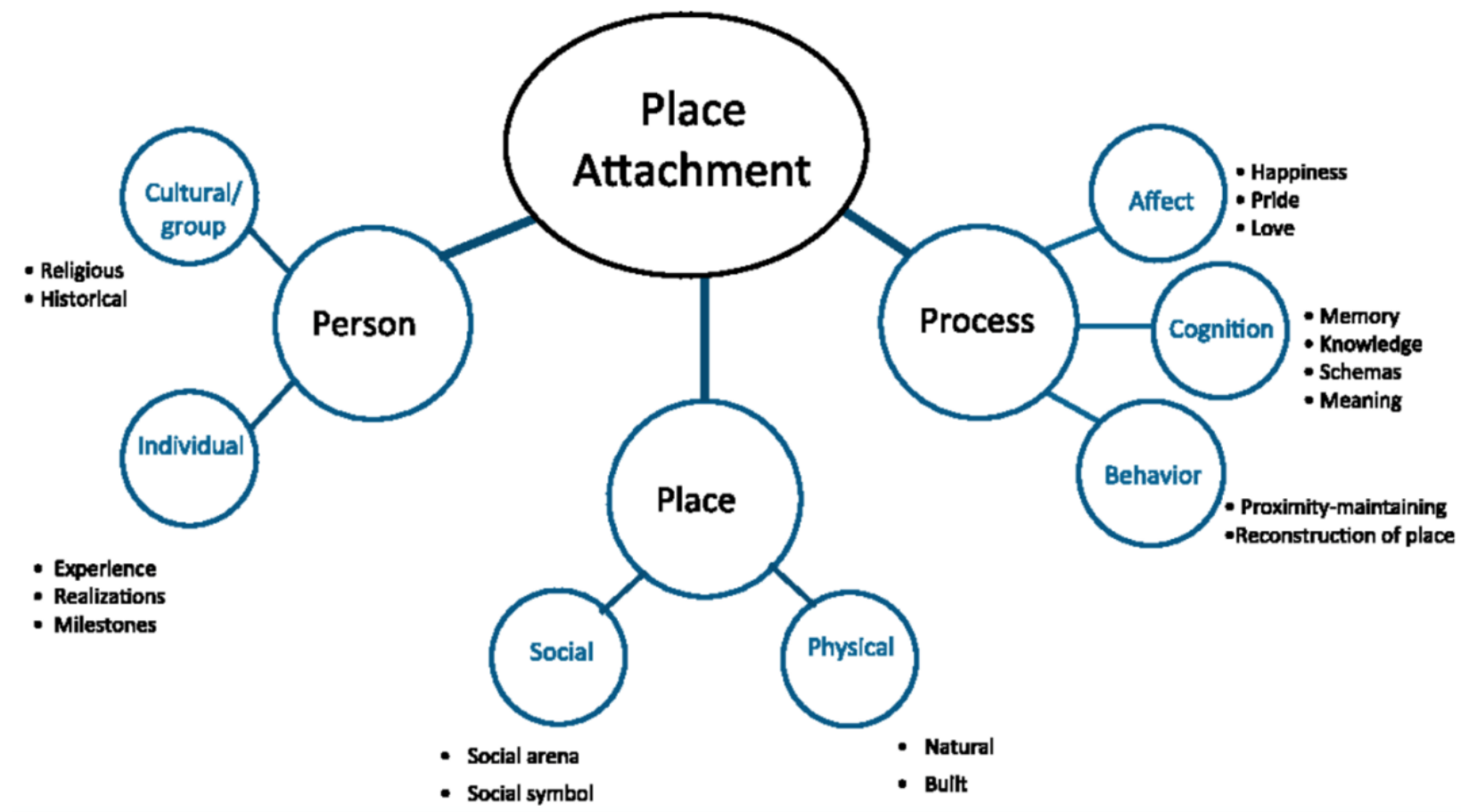


Figure 2: Psychology Framework to Discuss Place Attachment by Scannell and Gifford (2010: 2). This tripartite framework is useful in understanding the multi-faceted aspects of place attachment and helps to simplify and organize person-place bonding.

Diener and Hagen (2020) offer their own model of place-attachment, contending that geographers are positioned well to advance Scannell and Gifford's (2010) model through their innate understanding of process and place. Their place-based model affords geographers the ability to delve into connections between nature, social relations, and meaning [Figure 3]. Their model also allows for the assemblance of these three overlapping elements, which are created via action, experience, and perceptions of humans.

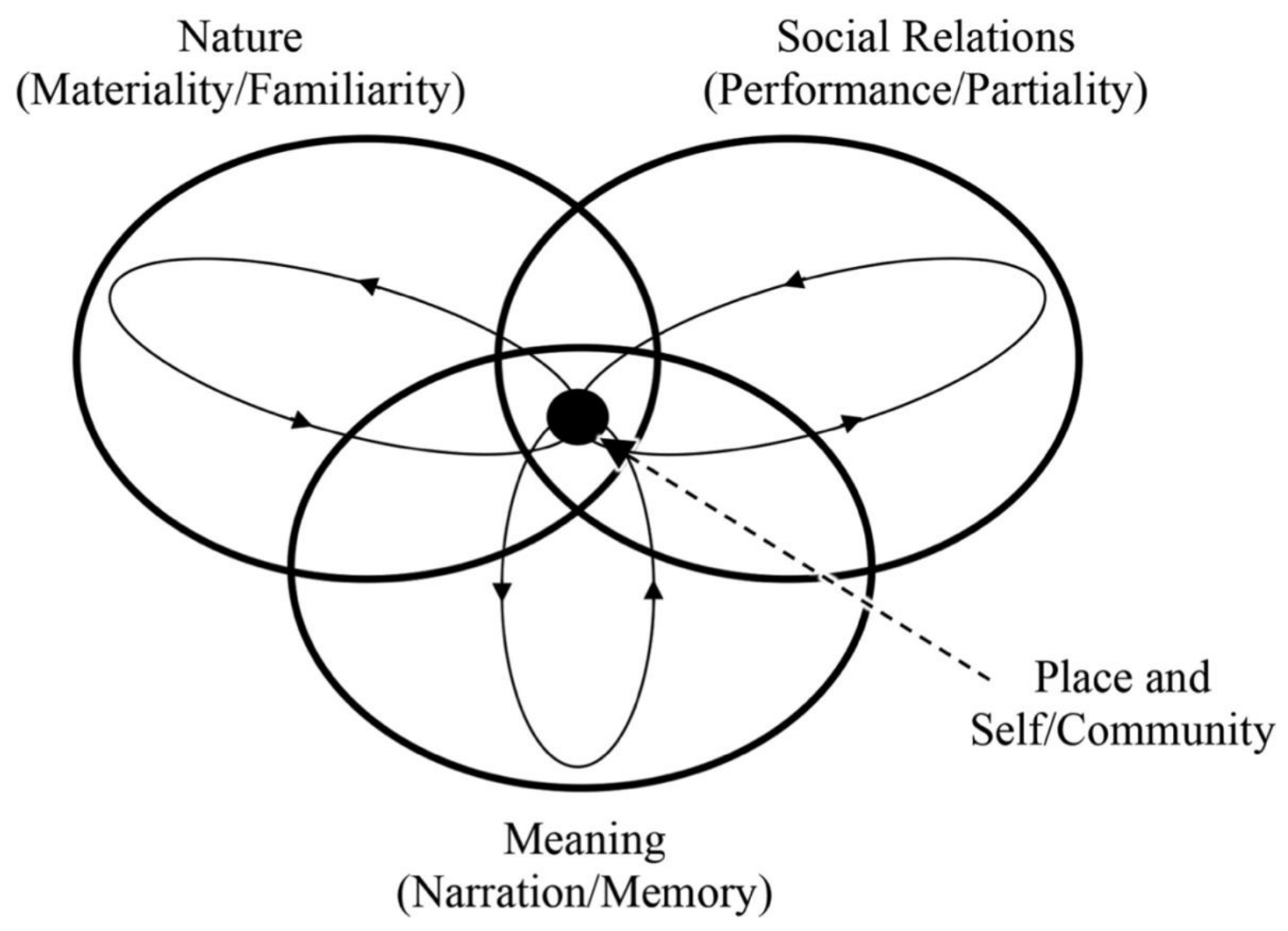

Figure 3: Place-Based Model of Place Attachment by Diener and Hagan (2020: 6)

Diener and Hagen's (2020) model is imperative to the research study on the sexual and placebased identities of LGBTQ+ students and their understandings of the environment and climate change. For instance, in my study LGBTQ+ students identify ways in which the broader LGBTQ+ community, with its embedded social relations, meaning, and materiality, produces 
place attachment. Likewise, due to the Appalachian environment within which their college or university is situated, LGBTQ+ students have a strong affinity to the natural environment. Within the natural environment, LGBTQ+ students work through their social relations with either other LGBTQ+ friends and peers or straight persons; these social relations oftentimes carry over from the everyday. Likewise, when thinking about how their identities influence their perceptions on climate change, LGBTQ+ students narrate experiences of privilege and how such experiences may act as a buffer to future climate change impacts within their immediate environment.

As climate change impacts continue to increase in frequency and intensity (Allen et al., 2018), humans are increasingly exposed to changes in their immediate environment through weather patterns, seasonality, and extreme events (Galway, 2019; Devine-Wright, 2013; Willox et al., 2012). Impacts will alter the access to and the quality of food and water supplies, as well as alter human health through illness, increased mortality, and physical and mental deterioration (Willox et al., 2012). Emerging literature highlights the emotional impacts too, as fear, worry, and hope towards climate change were evident in a plethora of studies through general human experience with and affinity to land and water, as well as through the place attachment to specific human activities such as fishing and foraging in a changing environment (Galway, 2019; Cunsolo and Ellis, 2018; Doring, 2017; Willox et al., 2012).

Loss of species, ecosystems, and locales due to climate change will drive what Cunsolo and Ellis (2018) define as 'ecological grief', in which mental health is deteriorated as a direct result of place-based, environmental impacts (p. 276). Climate-related weather events and disasters can be linked to a variety of mental health experiences, from strong emotional responses to heightened mood disorders. Threats and disruptions to sense of place and place attachment can also spur a loss of personal or cultural identity as well as ways of knowing (Cunsolo and Ellis, 2018: 277). Therefore, place-based attachment and place-based identity are essential aspects of understanding the impacts of climate change, for they act as indicators for climate-related health, adaptation, and mitigation strategies (Willox et al., 2012). 
Most research on climate change adaptation and response to climate change impacts such as extreme weather events or disasters emphasizes a material capacity to adapt (Allen et al., 2018), while non-material or subjective attributes of adaptation are less developed (Fresque-Baxter and Armitage, 2012). There is a preponderance for researchers to focus on the physical impacts of climate change and how these impacts affect human-environment interactions in the form of resources. Examples include sea-level rise and the precarious status of low-lying, developing nations such as Kiribati (Storey and Hunter, 2010) and Tuvalu (Mortreux and Barnett, 2009). Even on an international policy level, for example, the Intergovernmental Panel on Climate Change (IPCC) in its most recent Synthesis Report omitted any literature regarding the intersection of mental health and climate change (Pachauri et al., 2014).

Emotions can serve as frames for which future information, such as how climate change impacts may affect fishing in a lake, is interpreted (Nabi et al., 2018; Nabi, 2003). Negative emotions can further elicit greater risk perception and motivate individuals to inform themselves (Myers et al., 2012; Leiserowitz, 2006; Baron et al., 1994). Emotions also serve as a frame for assessing the potential for place attachment to shift across landscape and scale (Diener and Hagen, 2020). For example, natural-disaster victims might be unable to imagine themselves anywhere else; however, this placement is mobile in the sense that humans can adopt and abandon place within their everyday lived experience (Diener and Hagen, 2020: 17).

Feminist geographers are well-suited to produce research at the intersection of place attachment, emotions, and climate change, as traditional feminist geographical work has aimed to place the body and its emotions into knowledge production. The study of the body and its associated emotions have been widely undertaken by feminist geographers via their research processes and fieldwork (Sharp, 2009; Valentine, 2007; Longhurst, 1995). There is growing geographical literature around the concept of solastalgia (Ryan, 2016; Tschakert et al., 2013; Albrecht et al., 2007; Albrecht, 2005), or the distress produced by environmental change that directly impacts ones' place attachment. Solastalgia as a concept, much like ecological grief developed by Cunsolo and Ellis (2018), stands to better tie concepts of place attachment, emotions, and climate change together for the purpose of this research. 


\section{Life Course}

Life course is a theoretical concept often used to study lives (Elder et al., 2003). Stemming from sociology work in the mid-1920s, life course was produced out of the necessity to create an approach for longitudinal studies about the life history and future trajectories of individuals and groups (Volkart, 1951 in Elder et al., 2003: 3). Theorists argue that interactions between individuals and their social and physical environment help cultivate an individual's self-efficacy, or their beliefs about the world around them and how the world acts upon them (Gecas, 2003). Additionally, theorists such as Elder et al. (2003) assert that though social and physical environments can wield a certain amount of power over individual opportunity, individuals have the agency to exercise their self-efficacy, such as selecting, avoiding, or manipulating 'things' within their environment for their own personal gain or satisfaction (Gecas, 2003: 4). Aside from the physical environment, there are a variety of individuals, groups, and spaces that also aid in the development of individual self-efficacy. People such as family and peers and spaces such as schools or universities yield significant power over how life courses are structured. Life events and experiences are formed via human interactions among other humans and the spaces they produce and inhabit. These life events then help to shape one's life course.

Particularly within human geography, life course as a concept presumes that like-aged individuals are a part of similar stages in particular environments and spaces (Wimark, 2020). The concept is tied closely to the humanistic work of human geographers in the 1970s, such as the concept of lifeworld and thinking about space as important to life courses (Seamon, 1979). Though individuals or groups experience their lives in stages in ways that may be similar to their peers or of a broader population, these stages are experienced differentially in relation to space, place, and time (Elder et al., 2003). An individual's environments, locations, and places all influence and impact how that individual grows over time (Wimark, 2020). For example, Wimark (2020) comments that growing up within a certain place during a certain time produces sets of values and actions specific to that time and place (p. 181). He notes the example of gay men and lesbian women in the United States in the 1960s and how this particular group was exposed to rampant homophobia and stigmatization. As rebellions such as the Stonewall Riots in New York City and the creation of LGBTQ+ political activism groups such as Queer Nation 
began to form (Cohen, 2005), living with an open sexuality became prideful and persecution began to dissipate within major metropolitan areas (Wimark, 2020: 181). These experiences and formulations then cultivated a new life course for the next generation of LGBTQ+ youth who were more able to disclose their sexual identities and, in some cases, have more mobility and agency to move to areas where more LGBTQ+ acceptance occurred.

In another instance, life course approaches can be embedded in human geographical research on children's geographies and the geographies of aging. Worth's (2009) longitudinal study on blind adolescents' identities shifting as they become adults showcases how geographers are well equipped to integrate life course concepts into their research. Her study which focuses on life course via intersectionality highlights how identity directly influences self-efficacy, feelings and emotions in certain situations across space and time. Wimark (2019) in another study accentuates how emotions and feelings become embedded within life courses. Within his fieldwork in various locations such as Turkey, Ecuador, and Sweden as a gay man, he comments on the emotions he felt holding hands with other males in public. For instance, though homophobia is assumed to be commonplace in Turkey, Wimark (2019) notes that within particular city streets or sectors there is a budding queer community. Within this queer space of the city, Wilmark (2019) felt more comfortable holding hands with another gay man, his research partner, despite societal constraints to and vulnerability of performing this display. In another instance in Ecuador when a field guide held his hand, he felt uncomfortable and realized that this display of hand holding might evoke a negative response from those around him. Even in Stockholm, where open sexuality is commonplace, Wimark (2019) noticed how his then-partner who was from Ecuador did not to partake in public affection for fear of repercussion. This fear may stem from the specific time and space within which his partner lived in Ecuador, where there are different cultures, structures, and power dynamics. His vignettes showcase how space, as well as the societal norms and other constraints that produce individual response and reaction, is a necessary component to life course approaches.

The concept of life course is directly utilized in data analysis for this research. The concept allows for analysis and organization through loosely defined, key life transitions of participants. It is well-suited for research on LGBTQ+ undergraduate students as they transition from home to 
college spaces, and then transition from college to future workspaces. Transitioning from home to college space, these students' life courses are influenced by their family and peers, as well as the environment of Appalachia more broadly. As their queer identities are formed and shifted across space and time, these identities are embedded within their transitions. Emotions, feelings, and sense of belonging shift and attach themselves to identity formation over time and space. These transitions and life events then occur within the context of climate change in this research, as students are met with decisions, emotions, and perceptions of future life events in tandem with worsening climate impacts.

\section{Methodology}

The following section outlines research methodology, which includes epistemology, positionality and reflexivity, and proposed methods for completing research. I also present a mixed method approach I employ for my research project.

\section{Epistemology}

This research is grounded in feminist epistemology. Feminist epistemology views mainstream theories of human knowledge as one-dimensional and flawed due to the exclusion and misrepresentation of the contributions of women (Narayan, 2004). It challenges dualisms that propagate Western philosophical thinking such as reason versus emotion and universal versus particular. These dualisms directly adhere to positivist notions of objective science and rationality in which feminist scholars seek to dismantle and expand what defines 'knowledge'.

Feminist epistemology, therefore, asserts that knowledge is 'situated' in an entanglement of individual and collective identity, experience, location, power, and body (Mani, 1990; Mohanty, 1984). Feminist scholars argue that knowledge is not objective but rather subjective and situated. Situated knowledges are more accurate and reliable than objective knowledge that pretends to be 'neutral'; they also "promise more adequate, sustained, objective, transforming accounts of the world" (Haraway, 1988: 416). Through situated knowledges, individuals' partial perspectives of the world allow for the construction of objective knowledge. This knowledge is then developed and rooted in context, leading to greater objectivity. Likewise, a feminist standpoint allows 
scholars to further understand the contextual nature of knowledge, even if they themselves do not inhabit or occupy such contexts (Narayan, 2004; Hartsock, 2003).

Feminist epistemology makes use of situated knowledge to deconstruct hierarchical relationships present in academic research. Feminist scholars have challenged conventional knowledge production and have developed new or alternative approaches towards the construction of more equitable and inclusive research practice. Knowledge produced by and analysis conducted of marginalized groups or those who 'occupy the margins' (hooks, 1991) cannot be added to existing theoretical frameworks, but rather should be produced as standalone subject matter.

Early academic feminists challenged positivism and objectivity in the scientific approach and stressed that all research comes from an ideological or political standpoint (England, 2005). Field work and face-to-face interaction between researcher and research subject is not passive, as there is a budding relationship between the two, where ideas, cultures, and emotions are shared (Nagar, 2014). Methodologically, feminist researchers should be flexible in research questions, to alter or change questions as the research goes on and provide context to subjects' everyday lived experience (McDowell, 1992). Whether we are the researcher or the subject of research, we are 'situated' in difference; difference therefore informs our positionality.

\section{Positionality}

Since its inception, the discipline of Geography has been utilized as a tool for colonization, imperialism, and the destruction of both people and environment across the globe. Its white supremacist, racist, sexist, and homophobic past continues to seep into academic spaces, infiltrating conversations and research that effectively minimize and silence marginalized voices. At the same time, geographers have made significant contributions to critical social theory over the past several decades, producing a rich toolbox of knowledge that transcends various other disciplines. Though this colonial legacy has directly benefited me, a visibly cis-gender, white male, as a source of privilege, the discipline has afforded me ample opportunities to critically engage with climate change and to better understand my own positionality. 
Despite its past, Geography and the space of academia at large have challenged my perspective on the world and have illuminated connections to my own personal experience as a gay, (dis)abled man who has found refuge in nature. Struggling with my sexuality and hearing (dis)ability at a young age, I found solace in the environment. With this deep connection to nature at risk of being altered by climate change, I utilize my positionality of privilege and of marginalization to fight for a more just, equitable world within the context of academia.

My identity as a researcher and a geographer is complicit in, yet hopes to continuously deconstruct, the marginalization associated with those whose identities fall 'outside' the privileged white, heterosexual, cis-gender male identity that is often theorized and thought of as the central identity in mainstream, capitalist society. My identity, infused in an ever-fluid cornucopia of named identity categories such as socioeconomic standing, class, gender, and sexuality, directly positions me within my research project on climate change. Positionality is defined by markers of identity categories which have bearing on how research is conducted and how our individual or collective identities are formed (Smith, 2016). I approach my positionality as a continuous process that evolves over space and time and produces geographical knowledge as situated (see also Rose, 1993).

As a member of the LGBTQ+ community and a student of higher education, I embarked on this research to not only produce research that centers LGBTQ+ voice and thought, but to learn and further understand myself as well. As a LGBTQ+ college student with interests in climate change and human-environment interaction, I share an insider, deeper level of understanding with my participants who often have similar interests. This allowed for a unique understanding of their perceptions and beliefs of climate change and how their LGBTQ+ identity does (or does not) influence this understanding. This insight might not have been afforded had I not been a member of the LGBTQ+ community at-large.

Though I am no longer an undergraduate student, I empathized with my research participants' challenges, frustrations, and ventures into college space. Within my own undergraduate college experience, surrounding myself with young LGBTQ+ people outside the space of the home afforded a certain level of self-discovery that challenged how I viewed myself and my 
intersectional identities in different spaces. My undergraduate and graduate studies in Geography have furthered my understanding of environmental space, and my coursework in Women's and Gender Studies has allowed me to better recognize and theorize queer space and queer relationships with society.

I aim for this research to better illuminate the intersection between LGBTQ+ identity, perception, beliefs, and climate change for both academic and public audiences, and to help broader society understand marginality at-large and marginality coupled with climate change. My research also takes on a secondary utilization, one in which it illuminates queer identity in the often 'left-behind' and extracted space of Appalachia. It is not my intent to act as a voice for other LGBTQ+ students within Appalachia, but to share their stories and experiences through my own privilege as a white male in academia and as a public-focused writer. My research has been and will be disseminated via my position as a Campus Fellow for The Rachel Carson Council, a nonprofit, environmental non-governmental organization (NGO) that builds on the work and legacy of the late Rachel Carson (Rachel Carson Council, 2021). My approach to critical sustainability issues, one that encompasses health, environmental, societal, economic, and political spheres, mirrors that of Rachel Carson. Rachel through her work and through her identity as a lesbian environmentalist has given me the confidence to embark on such critical research.

Research participants are not simply a data source for researchers; instead, both the researcher and research participants are embedded in reciprocal relationships. Through interviews and focus groups, I was able to get to know participants on a personal level and treat them as equals rather than test subjects. Following England (1994), I aimed to challenge the power dynamics associated with researcher / researched relationships so often a characterization of research on marginalized populations. I did this via disclosing my own sexual and gender identities prior to the interviews. This is a part of an ongoing effort to build empathy and respect within the broader LGBTQ+ student community in Appalachia and to highlight the experiences and perceptions of participants in a non-hierarchal way so they too can benefit from the research and conversations had. These hierarchical boundaries held lesser power via my connections to participants as both a college-aged student in Appalachia and as a LGBTQ+ person. 


\section{Methods}

To answer to my research questions, I utilized what Creswell and Creswell (2018) define as an explanatory sequential mixed methods approach. Within this approach, a researcher first conducts quantitative research, analyzes the results, and then builds on the results to gather more detail using qualitative research (Creswell and Creswell, 2018: 15). I gathered data first through a quantitative survey that was administered at West Virginia University in the Spring 2020 semester between February and March. I analyzed the results of the survey (which will be explained in detail under the heading 'Survey') to locate broad patterns and perceptions of the general undergraduate population on global warming and climate change. Through these results, I re-formulated my case study, created an interview guide, and further carried out both semistructured interviews and focus groups.

A mixed methods approach was chosen under the guise that the utilization of both qualitative and quantitative methods would enhance the research validity (Eyles and Smith, 1998). In fact, different data types and modes of analysis afforded by both methods can illuminate potentially invisible meanings, relationships, and interactions (Elwood, 2010). As mentioned above, a quantitative analysis of collected survey data revealed broader patterns and relationships, while a qualitative analysis of interviews and focus groups provided further detail and produced meaning on a more precise scale that was not afforded through quantitative methods alone (Hanson and Pratt, 1995). Mixed methods have the potential to produce new knowledge through complimentary data types and sequential analysis (Creswell and Creswell, 2018).

In the following Methods section, I outline a case study approach and data gathered through a quantitative survey, semi-structured interviews, focus groups, and a field diary. The figure below [Figure 4] shows the transgression of research and research methods on a timeline from Spring 2020 through March 2020. 


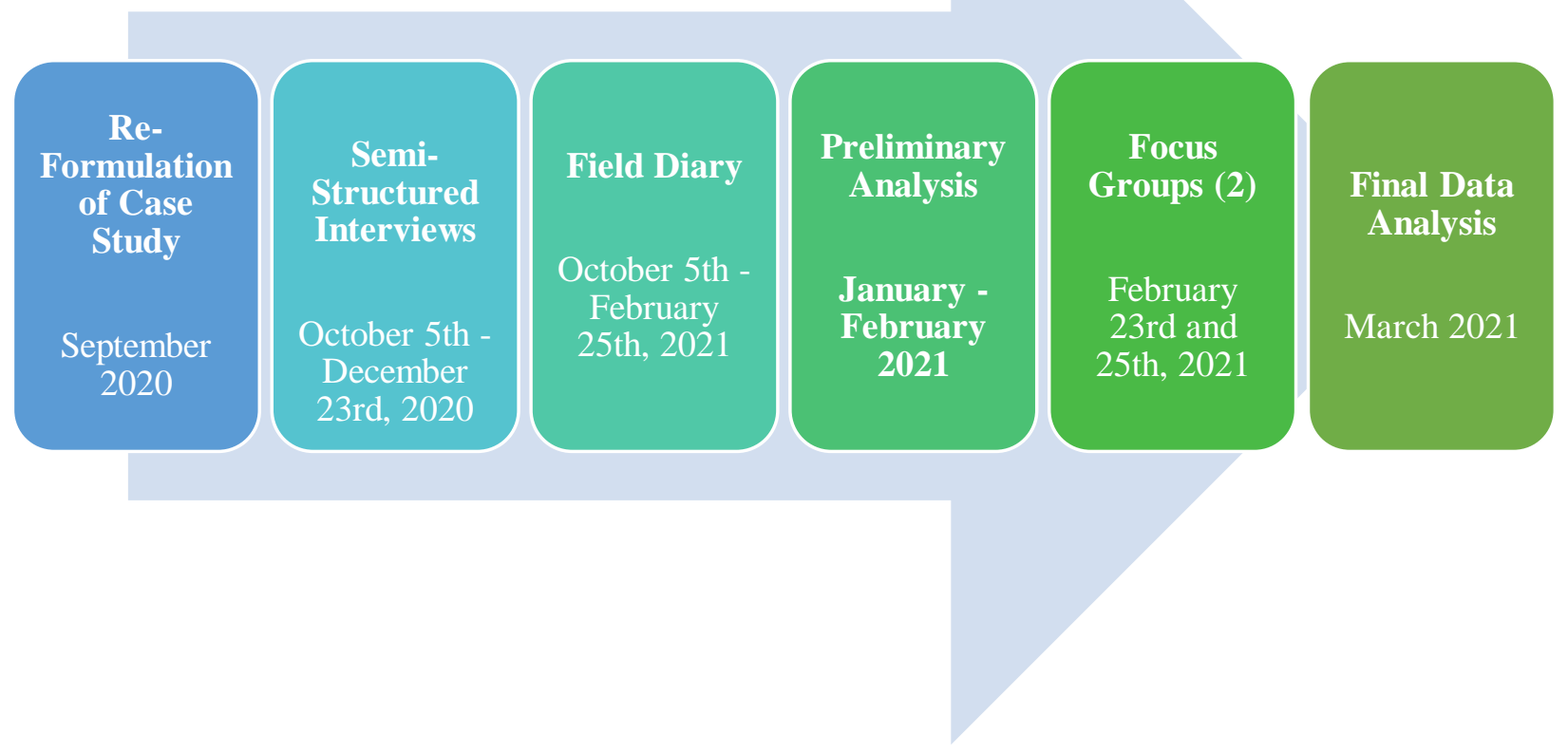

Figure 4: Timeline of Research Activities

\section{Case Study}

A case study is an empirical investigation bounded by a particular individual or group to better understand a specific phenomenon (Smith, 1978 in Mabry, 2012: 244). Conducting case studies, particularly in the social sciences and within the discipline of Geography, requires the practical selection of a site or sites that may guide investigation and reveal better understanding and analysis of the proposed research questions (Mabry, 2012). Case studies also have the potential to empirically research the intersection of social categories that are experienced in the everyday (Rodo-de-Zarate and Baylina, 2018: 551).

In my original proposal, the case study was limited to West Virginia University. However, the COVID-19 pandemic forced me to vacate the university space for approximately 6 months and to rethink the parameters of my research. After consulting my advisor and committee, I decided to expand the case study to include other large, public universities in the Appalachian region to afford greater participation and richer response. 
The case study was expanded to the following universities: West Virginia University, Penn State University, University of Kentucky, University of Tennessee - Knoxville, Appalachian State University, Virginia Tech, and Ohio University. Two universities - University of Tennessee Knoxville and Ohio University - did not garner any participants. I chose each of these universities based on both the size of their student population and their situatedness in the broader Appalachian region. Not to mention, these large, public universities were assumed to have larger LGBTQ+ student populations and resources than smaller universities in the region. Since I am a graduate student at West Virginia University and an alumnus of the Pennsylvania State University, I knew that both universities had both a large student population and a thriving LGBTQ+ community.

The Appalachian region stretches from Southern New York State through the northern reaches of Georgia and Alabama. I decided that a focus on the states with large swaths of land in central Appalachia [Pennsylvania, West Virginia, Virginia, Kentucky, Tennessee, Ohio, and North Carolina] would be beneficial for collecting a wide array of response from LGBTQ+ students.

Figure 5 shows a map of the Appalachian region as well as the universities a part of the study. 


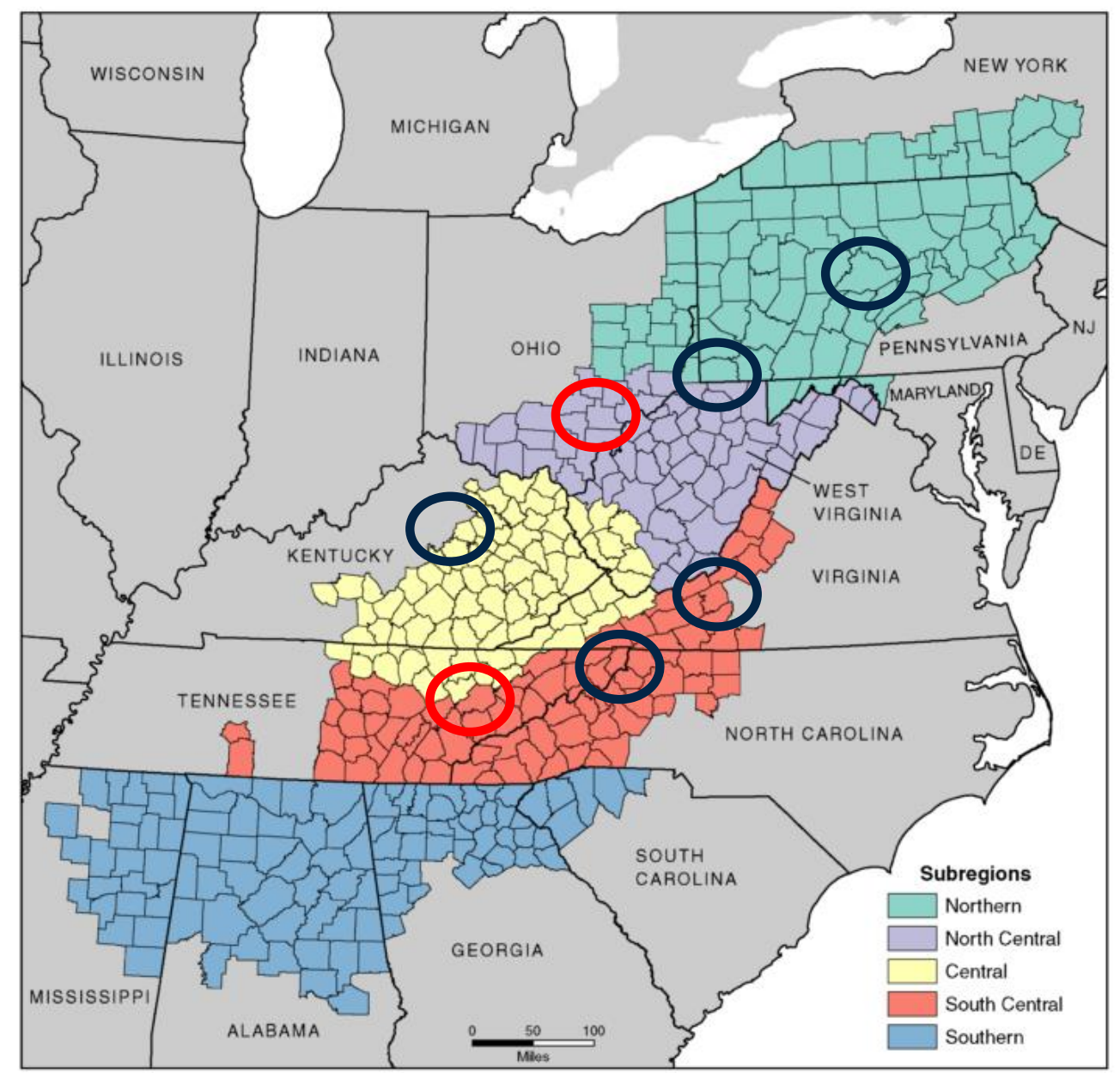

Map by: Appalachian Regional Commission, November 2009.

Figure 5: The Appalachian Region. Counties circled in blue include universities where participants were gathered from: Penn State University, West Virginia University, Appalachian State University, University of Kentucky, and Virginia Tech. Counties circled in red include universities were participants were recruited from but such recruitment was unsuccessful. (Appalachian Regional Commission, 2009)

A case study methodology was best suited for my analysis given that my focus is on undergraduate LGBTQ+ students in Appalachia. Preliminary data garnered through a quantitative survey at West Virginia University provided the basis for my study at-large. The survey directly aided my research through providing data on the perceptions and beliefs of climate change. Though the survey was utilized only at West Virginia University and the survey garnered general student body responses and not LGBTQ+-only responses, its results helped form the basis of my interview guide. 
A case study centered on multiple universities in the Appalachian region highlights the complexities of LGBTQ+ students' place-based attachments and identities. LGBTQ+ students on college campuses which occupy more rural and isolated geographic areas may develop placebased attachments to nature and the environment differently than LGBTQ+ students in more urban campus settings. Likewise, those who grew up in more rural areas who attend such universities within my study may think about their sexual identity in ways that are different than students who are from more urban, cosmopolitan areas outside the Appalachian region. With COVID-19, the case study was able to expand into the virtual space, allowing for a larger sample of participants.

In the following section, I recount lessons learned from a previous survey iteration and detail how the creation of an updated survey helped frame my interview guide.

\section{Survey}

A survey is a tool utilized within quantitative research design that "provides a numeric description of trends, attitudes, and opinions of a population by studying a sample of that population" (Creswell and Creswell, 2018: 12). Surveys can be utilized in cross-sectional studies through the use of questionnaires for data collection and are intended to help generalize from a sample to a broader population.

Between 2019 and 2020, Dr. Martina Angela Caretta and Dr. Nicolas Zegre received funding from the Appalachia Stewardship Foundation to conduct a project aimed at improving the curriculum of water management at West Virginia University. Utilizing experimental learning, they worked to improve students' understanding on climate change and its subsequent impacts on water resources, particularly in the state of West Virginia. A campus survey, modeled after the Yale Program on Climate Change Communication (YPCCC), was implemented in the following courses over the span of 4 semesters [Fall 2017, Fall 2018, Spring 2019, Fall 2019]: Forest Hydrology 444: Watershed Management and Forestry 140: West Virginia's Natural Resources. The campus survey consisted of twenty-one questions, taken directly from an earlier 2016 iteration of the Six Americas Survey by the YPCCC, and six personal questions. This campus survey iteration asked questions such as: "Do you think that global warming is 
happening?"; "Do you think citizens themselves should be doing more or less to address global warming?"; and "Personally, how well informed do you feel you are about the different consequences of global warming?" All twenty-one questions were multiple choice and often a part of a sliding scale opinion, for example: "Strongly Agree"; "Somewhat Agree"; "Somewhat Disagree"; and "Strongly Disagree."

It is important to note that the YPCCC uses the terms 'global warming' and 'climate change' interchangeably in their survey language to account for more effective communication. For example, 'global warming' is used in most questions based off of the assumption that the general U.S. public, across differing psychological, cultural, and political boundaries, is more familiar with the term as opposed to 'climate change' (Leiserowitz, 2006). In the interviews and focus groups conducted in this thesis research, however, 'climate change' was utilized solely. This occurred because 'global warming' is usually only associated with temperature increases, while 'climate change' is associated with temperature increases and other impacts due to a changing climate. In all, there were 178 total survey responses. I analyzed these responses to create a final project for Forest Hydrology 444: Watershed Management at the completion of the Fall 2019 semester. The analysis conducted will serve and inform Dr. Zegre's lesson plans in his courses on climate change moving forward.

Through the initial analysis, I realized that the campus survey utilized by Caretta and Zegre had limitations and needed to be recreated to account for updated changes to the YPCCC Six Americas Survey. The Six Americas Survey is updated by the YPCCC annually to gather more accurate data from participants nationwide. New questions such as: "Do you agree or disagree with the following statement: Global warming impacts U.S. national security," and "Do you agree or disagree with the following statement: The U.S. should drill for oil in the Arctic National Wildlife Refuge" were added to a newer iteration of the Six Americas Survey in 2019 to garner public opinion on recent changes to national environmental policy by the Trump Administration. Likewise, other questions involving politics and religion were added to better understand how they may or may not influence climate change perceptions. These questions were then added to the new campus survey I created to be dispersed in the Spring 2020 semester. In an effort to make the campus survey more holistic and inclusive, I also added personal 
questions regarding students' gender identity, sexual orientation, and ethnicity, among others, as they were absent from the previous campus iteration. This inclusion allows for more descriptive data to account for the various identities that make up the greater campus population.

Illuminating the perceptions and beliefs of climate change of those outside of the privileged, white heterosexual male identity stands to dismantle the imagined white, male-dominated space of the University.

The updated campus survey created for my research project was employed within a variety of courses at West Virginia University in the Spring 2020 semester prior to the COVID-19 pandemic. Since I had originally designed my case study to center on LGBTQ+ undergraduate students at West Virginia University only, the survey was initially administered to West Virginia University students only. Courses a part of survey dissemination included: Astronomy 106; Forestry 102; Geography 102; Geography 350; Geography/Geology 393; Geography 457; and Geography 693. Data collected within these courses better provided a generalizable understanding of perceptions and beliefs of climate change in students at West Virginia University, since most were introductory courses taken at the freshman or sophomore level. These courses have large class sizes and therefore could provide more survey respondents that act as a sample of the general student population, given that each student must complete a certain amount of introductory, general education courses.

Responses from the Spring 2020 semester totaled approximately 409, and since the overall student population of West Virginia University is roughly 22,000, I believe that my sampling frame, or the population that can be included in my survey, did not differ significantly from those excluded from the survey (McLafferty, 2016). Though respondents had been limited to those who have taken the courses that the survey was introduced in, the sample size can provide a more precise estimate of population characteristics given the percentage of the total student population of the University (McLafferty, 2016).

Below, I tease out a few sets of survey data that better informed my questioning in my interview guide. 


\section{Survey Analysis}

Aforementioned data from the updated campus survey iteration was analyzed to garner preliminary findings and provide background for my research project. To reiterate, the terms 'global warming' and 'climate change' have been used interchangeably in the survey based on the assumption by the Yale Program on Climate Change Communication (YPCCC) that the general public utilizes both terms in a similar context and meaning (Leiserowitz, 2006). Survey responses were recorded in the following courses: Astronomy 106 (115 participants); Forestry 102 (85 participants); Geography 102 (177 participants); Geography 350 (13 participants); Geography/Geology 393 (5 participants); and Geography 457/693 (14 participants). The total number of respondents was 409 , with roughly 380-404 respondents answering all survey questions. The demographics of survey respondents are illustrated in Figure 6 below.

\begin{tabular}{|c|c|c|c|c|c|}
\hline \multicolumn{6}{|c|}{ Survey Demographics } \\
\hline \multicolumn{3}{|c|}{ College Standing } & \multicolumn{3}{|c|}{ Ethnicity } \\
\hline Year & Response & $\%$ of Total Respondents & Type & Response & $\%$ of Total Respondents \\
\hline Freshman & 168 & $42 \%$ & Asian or Pacific Islander & 13 & $3 \%$ \\
\hline Sophomore & 107 & $27 \%$ & Black or African American & 11 & $3 \%$ \\
\hline Junior & 53 & $13 \%$ & Hispanic or Latino & 6 & $2 \%$ \\
\hline Senior & 60 & $15 \%$ & White / Caucasian & 331 & $87 \%$ \\
\hline Graduate Student & 10 & $3 \%$ & Other & 19 & $5 \%$ \\
\hline Total & 398 & $100 \%$ & Total & 380 & $100 \%$ \\
\hline \multicolumn{3}{|c|}{ Educational Attainment } & \multicolumn{3}{|c|}{ Gender Identity } \\
\hline Generation & Response & \% of Total Respondents & Identity & Response & $\%$ of Total Respondents \\
\hline First & 113 & $28 \%$ & Man & 211 & $53 \%$ \\
\hline Second & 147 & $37 \%$ & Woman & 182 & $46 \%$ \\
\hline Third & 98 & $25 \%$ & Trans / Non-Binary & 5 & $1 \%$ \\
\hline Fourth and Above & 41 & $10 \%$ & Other & 2 & $1 \%$ \\
\hline Total & 399 & $100 \%$ & Total & 400 & $100 \%$ \\
\hline \multicolumn{3}{|c|}{ Age } & \multicolumn{3}{|c|}{ Sexual Orientation } \\
\hline Range & Response & \% of Total Respondents & Orientation & Response & $\%$ of Total Respondents \\
\hline $17-19$ & 215 & $54 \%$ & Heterosexual & 353 & $89 \%$ \\
\hline $20-21$ & 117 & $29 \%$ & Queer & 42 & $11 \%$ \\
\hline $22-23$ & 43 & $11 \%$ & Total & 395 & $100 \%$ \\
\hline $24-26$ & 18 & $5 \%$ & & & \\
\hline 26-Older & 5 & $1 \%$ & & & \\
\hline Total & 398 & $100 \%$ & & & \\
\hline
\end{tabular}

\section{Figure 6: Demographics of Campus Survey Respondents}

In terms of overall perceptions and beliefs, the majority of students believe that global warming is happening $(91 \%$; 371) while 62\% (252) believe that global warming is caused by both natural changes in the environment and human activities. $75 \%$ (306) were 'somewhat worried' or 'very worried' about global warming, and 78\% (317) thought that they would be personally harmed by global warming in some capacity. Interestingly, 260 participants (65\%) 'strongly agree' or 
'somewhat agree' that religion influences how people think about global warming, and 368 (91\%) 'strongly agree' or 'somewhat agree' that politics influence how people think about global warming. The answers to such survey questions helped inform questions \#10 and \#11 of my interview guide. Below, I present a few survey questions and their responses that have the most direct application to the research gaps that I attempt to address in my research project.

Questions 5, 6, and 7 of the survey went hand-in-hand with one another and garnered opinion on when global warming would start to harm people: 1) in developing countries; 2) in the United States; and 3) in Appalachia. I present these three survey questions together because they directly tie into my research at the intersection of place-based identity and climate change, as well as illuminate a limitation of the survey data. Survey responses for each of these questions are illustrated via charts below in Figure 7.

Q5: When do you think global warming will start to harm people in developing countries?

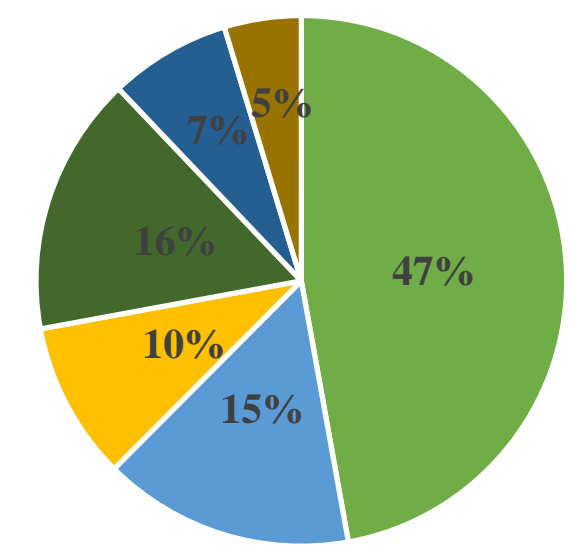

- They are being harmed now. = In 10 years.

- In 25 years. - In 50 years.

- In 100 years. $\quad$ - Never. 
Q6: When do you think global warming will start to harm people in the United States?

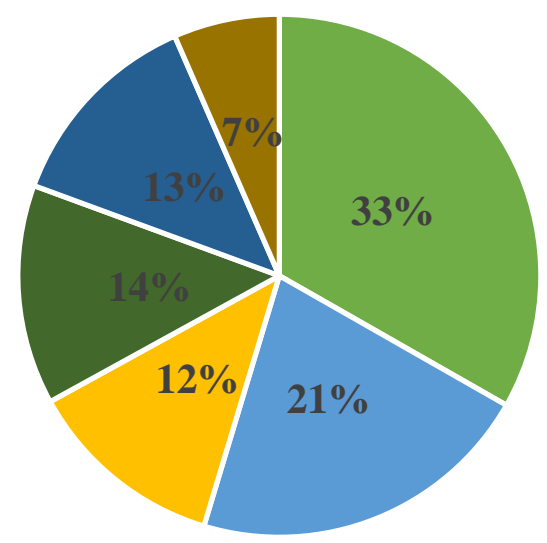

- They are being harmed now. $\square$ In 10 years.

- In 25 years. - In 50 years.

- In 100 years. $\quad$ Never.

Q7: When do you think global warming will start to harm people in Appalachia specifically?

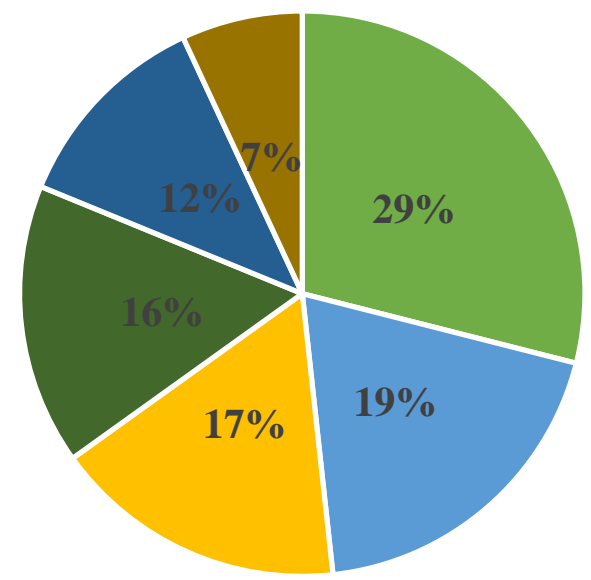

- They are being harmed now. " In 10 years.

- In 25 years. $\quad$ In 50 years.

- In 100 years. $\quad$ - Never.

Figure 7: Selected Campus Survey Questions and Responses 
By looking at responses for these three questions, students believed that global warming is already affecting developing countries more than the United States and, more granularly, Appalachia. Likewise, there are varied responses in regard to when global warming impacts would occur in all three places in the future, prompting questions as to whether students perceive global warming and climate change as 'out there' problems. In response to question 7 specifically, it seems that students are less sure of the timing and/or impact of global warming in Appalachia yet seem more aware or sure of the timing and/or impact for both developing countries and the United States. It is of note that more students, between 7-8\% of survey respondents, answered 'Never' to the question asking when global warming would harm people in the United States (26 people) and Appalachia (28 people) respectively; this was less than the number of students that answered 'Never' when asked the same question but in relation to developing countries (19 people). This again points to students seeing global warming and climate change as 'out there'.

However, 78\% (317) survey respondents answered an earlier question that they believed global warming would harm them personally, but it seems that students are unable to materialize this future harm temporally. These survey questions are, in fact, too limiting because they are unable to characterize why students answered in a certain way, and how global warming impacts may tie to students' identity. My research aims to address these questions though the use of interviews. This grouping of questions directly influenced questions \#12 and \#15 of my interview guide, which can be found in [Appendix A]. Question \#12 asks "What does climate change 'look like' to you? Do you think this view differs from others who live in [State] and Appalachia more broadly? What about people in the United States outside Appalachia?" Question \#15 asks "How might climate change impact where you live, work, and play? What concerns do you have with future climate change impacts affecting you personally?”

Responses to Question 15 on the survey at West Virginia University directly influenced interview guide questions as well. The question asked students to state their opinion on global warming and whether humans would be able to successfully stop its effects. Survey responses for this question are illustrated below in Figure 8. 


\section{Q15: Which of the following statements comes closest to your} view?

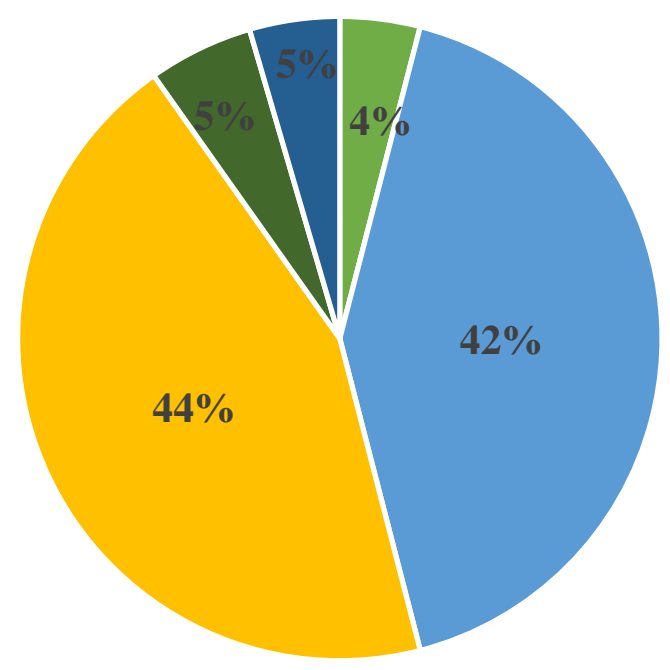

- Humans can reduce global warming, and we are going to do so successfully.

- Humans could reduce global warming, but it's unclear at this point whether we will do what's needed.

- Humans could reduce global warming, but people aren't willing to change their behavior, so we're not going to reduce global warming.

- Humans can't reduce global warming, even if it is happening.

- Global warming isn't happening.

\section{Figure 8: Selected Campus Survey Questions and Responses}

These responses are studied further via semi-structured interviews and focus groups, as they directly correlate to how students might perceive global warming impacts in their environment. They also correlate to how these impacts might affect their emotions and mental health. These responses via the survey show that students envision that there will be personal consequences associated with climate change. However, the survey does not illuminate this data, or data on how students feel about the consequences and actions associated with climate change. In turn, these survey questions 'fix' responses which may not illustrate how identities influence responses too (Johnston, 2003). My interview guide, therefore, asked questions that would elicit open-ended responses. This survey question directly influenced the creation of Question \#10, 
Question \#11, and Question \#13 on my interview guide: Question \#10 asks "What do you think of when you think of climate change?"; Question \#11 asks "Are these thoughts at the forefront of your daily life?"; and Question \#13 asks "How does this view or picture of climate change make you feel?"

These survey questions illustrate that sole quantitative research design is too limited to adequately address the research questions. Therefore, the survey data must be coupled with qualitative data collected from interviews and focus groups to achieve stronger validity (Eyles and Smith, 1998). The interviews helped gather data specifically on individual experiences and how climate change impacts might be felt on a personal level, from the body to the immediate environment. Notably, the interviews and focus groups also allow for a deeper investigation of how the immediate environment may shape and/or influence place-based attachment and identity. The explanatory sequential mixed methods approach can potentially allow for the unearthing of hidden relationships and meaning within my datasets as well (Creswell and Creswell, 2018; Elwood, 2010).

It is important to note that the initial analysis of quantitative survey data was not utilized within the results of this thesis. Rather, this analysis was conducted prior to shifting the case study from LGBTQ+ undergraduate students at West Virginia University to students at other large, public institutions in Appalachia as well. Therefore, survey data analysis was only utilized to create semi-structured interview questions and is utilized within this thesis to inform research design.

In the following section, I provide a depiction of sampling techniques that I employed to gather research participants.

\section{Sampling}

I utilized two sampling methods: theoretical sampling and snowball sampling. Theoretical sampling allows the researcher to set sampling criteria which can be revised as research continues and allows the researcher to stop sampling when criteria is met (Curtis et al., 2000). In order to participate in my research study, participants must be currently enrolled as a student at one of the following universities: West Virginia University, Penn State University, University of 
Kentucky, University of Tennessee - Knoxville, Appalachian State University, Virginia Tech, or Ohio University. They must also be pursing an undergraduate degree and must identify as a member of the LGBTQ+ community.

Through this sampling criteria, I elicited snowball sampling. Snowball sampling is a commonly employed method in qualitative research where a participant gives the researcher a name of at least one other potential participant; that participant then provides the name of at least one other potential participant, and the sample size of the research project grows (Handcock and Gile, 2011). Snowball sampling was best suited for the research project given the sensitive nature of the topic, as well as the vulnerabilities associated with identifying as LGBTQ+. Though I myself am a part of the LGBTQ+ community, this sampling technique was beneficial to reach individuals in the community that I may not know of.

At the beginning of my study, I reached out to LGBTQ+ Centers at my target universities and asked them to share my study with their email listservs. This action was particularly helpful at West Virginia University, as I gained 5 participants via this avenue. I also had my thesis committee members send out personalized emails to their colleagues at the universities within my case study and asked them to share with their students and departments my call for participants. Through this avenue, I gained 5 more participants.

Here, I'd like to stress the importance of social media within my sample techniques. In order to reach participants, I utilized a variety of different avenues. I curated a list of university-affiliated, geography-affiliated, and LGBTQ+ affiliated Twitter handles and created tweets for my advisor and I to share on the platform. Though this method did not elicit any participants, it helped form the basis of other social media outreach campaigns. I utilized my position as the Appalachia Regional Fellow with Citizens' Climate Lobby to send out emails to approximately 400 students who signed up for email alerts, and I posted in a higher education Facebook group that over 1,500 people are a part of. I also was able to reach out to the LGBTQIA+ group within Citizens' Climate Lobby to reach approximately 100 members. 
Instagram by far was the most prominent social media platform that helped to elicit participants. Utilizing my personal account, I created an Instagram post looking for participants and had some of my friends share it on their Instagram Stories. This avenue was wildly successful, as I had approximately 20,000 Instagram users interact with my story in some way. Through this sharing, I was able to directly gather approximately 15 more research participants. Through them I was able to elicit more participants via snowball sampling. In a way, these gatekeepers helped me identify others who might have had beneficial insights into my research at their respective universities.

In the following section, I outline the necessity for semi-structured interviews following survey data collection.

\section{Semi-Structured Interviews}

A semi-structured interview is a verbal interchange where the interviewer elicits information from the research participant through a set of pre-determined questions (Creswell and Creswell, 2018). Though the interviewer has a list of questions to utilize within the interview, semistructured interviews offer research participants the chance to create in-depth answers to questions they deem important. The semi-structured nature also allows the interviewer the ability to facilitate a dialogue within which the interviewer can gain partial insight into the behaviors, emotions, and opinions of research participants.

28 semi-structured interviews were carried out to better inform the responses collected through the survey and to 'break down' the fixing of identities and experiences (Johnston, 2003). Though the survey was beneficial in collecting data at West Virginia University to better inform perceptions on a University-wide, general student body scale, employing a quantification of identity categories such as gender identity, sexual orientation, and race may fix false subjectivities (Johnston, 2003). Interviews granted the opportunity to ask LGBTQ+ undergraduate students in Appalachia about their experiences and perceptions firsthand rather than focusing on the collected objective, multiple-choice answers from the survey. 
The universities represented and the number of interviewees at each institution are as follows: West Virginia University [10 participants], Pennsylvania State University [8 participants], Appalachian State University [7 participants], Virginia Tech [2 participants], and University of Kentucky [1 participant]. Two universities, University of Tennessee - Knoxville and Ohio University, did not garner participants despite numerous recruitment attempts. For example, I was in direct contact with staff at the University of Tennessee - Knoxville's LGBTQ+ Center to distribute the call for participants, but these efforts did not produce any contact with me.

Figure 9 below encapsulates demographic data of interview participants with regards to their ethnicity, gender identity, and sexual orientation. It is important to note that such data was provided via asking the question: "How do you self-identify?" Participants were able to disclose as much information about their identity as they wished.

\begin{tabular}{|c|c|c|}
\hline \multicolumn{3}{|c|}{ Interview Demographics } \\
\hline \multicolumn{3}{|c|}{ Ethnicity } \\
\hline Type & Respondents & \% of Total Respondents \\
\hline Asian or Pacific Islander & 1 & $4 \%$ \\
\hline White / Caucasian & 26 & $93 \%$ \\
\hline Black or African American & 1 & $4 \%$ \\
\hline Total & $\mathbf{2 8}$ & $\mathbf{1 0 0 \%}$ \\
\hline \multicolumn{3}{|c|}{ Gender Identity } \\
\hline Identity & Response & \% of Total Respondents \\
\hline Man & 8 & $29 \%$ \\
\hline Woman & 18 & $64 \%$ \\
\hline Trans / Non-Binary & 2 & $7 \%$ \\
\hline Total & $\mathbf{2 8}$ & $\mathbf{1 0 0 \%}$ \\
\hline Orientation & Response & $\mathbf{\%}$ of Total Respondents \\
\hline Bisexual & 8 & $29 \%$ \\
\hline Gay & 9 & $32 \%$ \\
\hline Lesbian & 4 & $14 \%$ \\
\hline Queer & 7 & $25 \%$ \\
\hline Total & $\mathbf{2 8}$ & $\mathbf{1 0 0 \%}$ \\
\hline
\end{tabular}

Figure 9: Interview Participant Demographics 
It is also of importance to note that cis-gender, male and female-identifying participants utilized the term 'gay' to describe their sexual orientation and to describe themselves in relation to straight friends, classmates, or strangers in the built and natural environment. They also utilized the term 'gay' to describe other LGBTQ+ people and their experiences with climate change. Other participants utilized the term 'queer' as an umbrella term to describe their gender identity and sexual orientation. A few of the participants who described themselves as queer also noted that they are still in the process of figuring out both their gender identity and sexual orientation, claiming that they are 'a work in progress.' This speaks to the fluidity that LGBTQ+ participants may embody in relation to their identity.

The semi-structured interviews allowed me to directly speak with LGBTQ+ undergraduate students at various large, public universities in Appalachia. The interview guide [see Appendix A] consisted of 17 open-ended questions that prompted participants to speak about their lived experience as well as their place-based attachment and identities in and around the college space. The interview guide was directly created via data analysis of survey data collected at West Virginia University and was broken into four sub-sections. First, students were asked about their personal life via questions regarding where they are from, what they study in college, and how the environment is infused in their upbringing and college experience. Questions such as: "Where are you from?"; "What brought you to *college town*?"; and "What do you study at *university*?" were posed. These questions are noted in Appendix A under the subheading 'Personal'. Then, students were asked questions about their gender, sexual, and racial identity and how these identities may or may not intersect with understandings of and being in the immediate, natural environment. These questions are noted in Appendix A under the subheading 'The Environment and LGBTQ+ Identity'. Then, students were asked questions about their perceptions of and emotions surrounding climate change, as well as how they believed their identity intersects them. These questions are noted in Appendix A under the subheading 'Climate Change'. Then, students were asked questions about how climate change might impact their livelihood in the future through their work, identity, environment, and extracurricular activities. Further, students were asked how their college or university could better address future climate change impacts. These questions are noted in Appendix A under the subheading 'Climate Change and Place-Based Attachment'. 
Interviews lasted approximately 40-60 minutes in length and were conducted via Zoom. Advances in online, video-conferencing technologies such as Zoom afforded the ability to interview research participants who were not in geographic proximity to me. In a recent study by Archibald et al. (2019) on nurses utilizing Zoom found general agreement among both researchers and participants that Zoom was quite useful for conducting qualitative interviews, and that most participants preferred Zoom over other methods of interviewing such as in-person, over-the-phone, and over-email (p. 3). Like Archibald et al. (2019), I too found that using Zoom was not only user-friendly and simple for college-aged students to operate in the middle of a pandemic, but also saved me from time and access constraints. The online format was preferred because I was able to have a face-to-face conversation with participants in a safe manner. The online format also allowed me to use closed captioning to better hear what participants were saying in their interviews and provided transcription ease. Details involving transcription of interviews and data analysis are noted in a later section.

In the next section, I describe the utilization of focus groups.

\section{Focus Group}

Focus groups can be characterized as a group interview or a collective conversation in which participants interact with both each other and the moderator (Ryan et al., 2014), and can be employed to examine a particular issue with a homogenous group [in this case, LGBTQ+ undergraduate students] in detail. Focus groups were utilized to better inform the individual, semi-structured interviews and to garner collective views regarding specific place-based attachment, identity, and perceptions.

In all, I conducted 2 focus groups. The first focus group was on Tuesday, February $23^{\text {rd }}$ and had 9 participants. 2 participants who identified as queer were friends of one of the interviewees and had not been interviewed themselves. The second focus group was on Thursday, February $25^{\text {th }}$ and had 7 participants. 1 participant who identified as queer had not been interviewed prior. All interview participants were given a Google Form to mark their availability for a focus group. The focus group was completely optional for interview participants, and interview participants were encouraged to ask LGBTQ+ friends at their prospective universities if they would like to partake. 
After the Google Form was filled out by interested participants, I split up the participants based on their availability and to also limit the amount of people who knew one another in the same group. Approximately 3 participants in each focus group were from West Virginia University, 2 participants were from Penn State University, and 2 participants were from a mix of Appalachian State University and Virginia Tech.

The focus groups were a hybrid approach of a scoping focus group and a narrative focus group. I employed a semi-structured conversation to generate a mix of personal opinions and collective experiences regarding place-based attachment and identity (Ryan et al., 2014). This hybrid approach was useful in addressing the needs of participants through descriptions of their own lives, while allowing myself as the moderator to take an empathic stance (Ryan et al., 2014: 337 338). Within the focus group, I showed a PowerPoint of quotes I pulled out from reoccurring themes across most interviews. I asked open-ended questions regarding the quotes, which can be found in Appendix B. I then allowed participants to have an open discussion about their experiences.

I am aware that participants may have met each other for the first time through the focus group, or that they may already have prior knowledge of one another through both formal and informal interactions within the LGBTQ+ community. It is important to note that prior knowledge of others may alter group dynamics and can create vulnerabilities amongst participants in focus group settings (Hoffmeyer and Scott, 2007). This, however, was not felt by me during facilitation. Still, I understand that the age of the participants, the location of the focus group, and the sensitivity of the topic being discussed might have influenced the nature of focus group interaction and discussion (Hopkins, 2007: 531).

The sensitivity of the topic was of utmost importance, as my research draws on the geographies and identities of LGBTQ+ students, which can be considered a socially marginalized group. I attempted to mitigate the sensitivity of the topic through creating a reciprocal relationship with each of the participants individually and then through creating a safe space to conduct the focus group in (England, 1994). Likewise, as the facilitator of the focus groups, I made sure that all participants were able to equally use the space to speak of their experiences. This space directly 
correlates to understanding lived experience as a means of conducting intersectionality (Rodode-Zarate and Baylina, 2018: 551).

While conducting interviews and focus groups, I kept a field diary of my initial reactions and impressions prior to, during, and after completion. In the following section, I outline the importance of utilizing a field diary.

\section{Field Diary}

A field diary is a form of participant observation that allows the researcher to document and reflect upon the places and people they study. It can be a site where the researcher makes connections to theoretical readings, impressions, ideas, and interpretations (Watson and Till, 2010: 8). The field diary was beneficial for documentation of observations before, during, and after human interaction via interviews and focus groups, as all of my observations may not have been transferable to the collected audio recordings. These richer observations allowed for better description and reflexivity during the research process, a tenant of feminist methodology. Reflexivity is an act of critical self-reflection of how a researcher's thoughts, experiences, and biases influence the research process and the relationship between researcher and research participant 'in the field' (Sharp and Dowler, 2011; England, 1994, 2005). Reflexivity is a critical piece of fieldwork and can lead to insights and new hypotheses within research. My use of a field diary also acted as 'background coding' in which I generated codes by-hand based on my observations and applied these in NVivo 12, a qualitative data analysis software. Coding in NVivo 12 will be discussed in detail in the data analysis section.

\section{Validation and Member Checking}

Validation in qualitative research takes can be achieved (1) through triangulation and (2) by using methods that validate one another. Data triangulation is commonly utilized as a mixed method approach that allows the researcher to investigate inconsistencies between different data sets and to help confirm or explain their conclusions (Taylor, 2016). The utilization of different methods may increase the validity of research findings and the understanding of the phenomenon being studied. Data collected via the survey, interviews, focus groups and field diary was triangulated to achieve greater transactional validity. 
Transactional validity is an interactive process between the researcher, research participant, and the data generated and collected through the research process, and aims to achieve a higher level of accuracy (Cho and Trent, 2006). This can be achieved through an in-depth revisiting of facts, feelings and experiences throughout the research process. In this sense, truth is not an objective account of reality, but rather a subjective account of a participant's own reality (Koelsch, 2013).

Member checking is a form of transactional validity when data, interpretations and conclusions are tested with members of the groups in which data was originally obtained (Lincoln and Guba, 1985). This process can occur both informally and formally. Informal member checking can occur when the research participant is given relevant sections of the research project, such as a transcription of their own interview, and can comment on the accuracy of the transcription (Koelsch, 2013). Formal member checking can occur when the researcher creates a report of preliminary findings in the form of a booklet, summary, or similar medium to distribute to research participants for revision (Lincoln and Guba, 1985). A member check can also be utilized to equalize power relationships between researcher and research participant (Caretta, 2016).

I conducted informal member checking after transcription of the semi-structured interviews with each of my participants. Each participant was able to read and comment on the interview transcription via email, as well as edit the document of their choosing and email it back to me. Of the 28 participants, approximately 6 edited their transcription in some way, while the others did not wish to edit and told me what I transcribed adequately encompassed their thoughts. After the focus groups, I also sent out the transcription to participants and asked if they'd like to edit.

Though participants might not have wanted to respond or provide comments, I remained reflexive in my research process (England, 2005). Member checking in this scenario, where participants do not respond, may act as a limitation to achieving greater transactional validity. I triangulated my interview and focus group data as well as my field diary via the avenues outlined above. 
After the completion of interviews, I conducted data analysis that helped inform my focus groups.

\section{Data Analysis}

Following all semi-structured interviews, I employed a mix of coding strategies. Coding is a form of data analysis in which the researcher identifies general patterns, clarifies connections and relations, develops possible insights, and refines ideas (Watson and Till, 2010: 9). Coding can also help to develop big-picture themes which directly correlate to the conceptual framework of my research project (Cope and Kurtz, 2016). I blended hand-coding techniques with coding in data analysis software to ensure that I remained reflexive and recursive. Though the medium of coding does not determine the rigor of my analysis (Baxter and Eyles, 1997), my research project benefits from a blending of data analysis methods that help validate one another.

After each interview, I transcribed and coded for re-occurring words and phrases that were prevalent. Codes provide various categories that help identify broader themes and concepts amongst responses; these themes and concepts can be applied directly to the case study. I coded each interview by hand for key words or phrases that created patterns in the overall dataset. Through this close reading of the text, line-by-line and word-by-word, I produced concepts that 'fit' my data set (Cope and Kurtz, 2016: 652). My advisor, lab mate, and I each read the interview transcriptions and made our own code lists. This process produced intercoder reliability, in which independent coders agree on a similar coding schema through a close read of the written interview content (Cho, 2011). When the three of us met to discuss our independent code lists in late January, there were significant overlaps in codes. Therefore, high intercoder reliability was achieved. The code list consisted of different themes which spoke to the research questions at hand.

Utilizing the list of codes that I found important and meaningful for the research project, I inserted such codes into NVivo 12, a qualitative data analysis software. A careful reading of all data documents in NVivo 12 allowed for greater reflection and iteration, as new or subsequent codes emerged from the original list of codes produced through hand-coding. Using NVivo 12 
also allowed for the opportunity to refine or reframe my research project as a whole (Saldana, 2016).

Once transcription and coding were completed and data had been preliminary analyzed, I utilized the coding to tease out important themes and quotes. Certain quotes were utilized within the focus groups to stimulate dialogue among participants and to achieve greater validity. Such quotes are noted in Appendix B. Quotes were also used for articles written for The Rachel Carson Council, as well as other academic pursuits outside of the thesis itself.

As I re-read my preliminary results following the interviews and focus groups, I realized that the concept of life course, as discussed in my conceptual framework, was well suited to analyze my overall results. After familiarizing myself with the concept and re-reading my interview guide, it became apparent that participant experiences fell into three, overlapping 'courses': before college, during college, and after college. Each of the four subgroups of questions from my interview guide, as it was discovered via data analysis, fell into these overlapping 'courses'.

A more in-depth discussion of framing the results through the analytical tool of life course is discussed in the following section.

\section{Results}

This section incorporates findings from interviews, focus groups, and field diary data. The data is presented through a life course approach as discussed in the conceptual framework and data analysis sections of this thesis. The life course concept is directly embedded in the way in which results are presented below, as shown in Figure 10. Participants' lives, experiences, and events are split between three separate events within a particular space and time: before college, during college, and after college. However, it is important to note that these event demarcations are fluid, as certain experiences such as sexual identity formation are not rigid and instead ebb and flow within different environments and contexts. The data follows a life course through participants' identity formation and affinity to the natural environment, which are demarcated as 'before college'; participants' experiences and understandings of their identity, the environment, 
and climate change 'during college'; and participants' perceptions of future climate change impacts and the emotions associated with climate inaction and uncertainty 'after college'. All participants spoke to their experiences along this path.

Research questions coincide with these life course events. Sexual and place-based identities, which are formulated both before and during college, influence participant understandings of the environment. These experiences and events answer to research question 1. Likewise, these identities manifest within emotions and perceptions of environmental change and climate change during college, as participants are exposed to more environmental education and could better identify and understand why climate denial and 'different' climate change perceptions easily permeate Appalachian spaces. These experiences, events, and perceptions answer to research question 2. Then, emotions and perceptions carry over to thoughts and feelings about future climate change impacts, as participants understand how the privileges their identities produce in space over time will influence how climate change affects them personally. These perceptions and emotions answer to research question 3.

The data selected below best represents the research questions and is organized by particular life events. As aforementioned in the conceptual framework, young people are living in a time of multiple transitions (Worth, 2009). Transitioning from spaces of home to spaces of higher education, to then future spaces of work and leisure, produces an array of experiences and events for young adults. Understandings of the immediate environment, and how climate change may or may not affect this immediate environment, are embedded within participant's sexualities. 


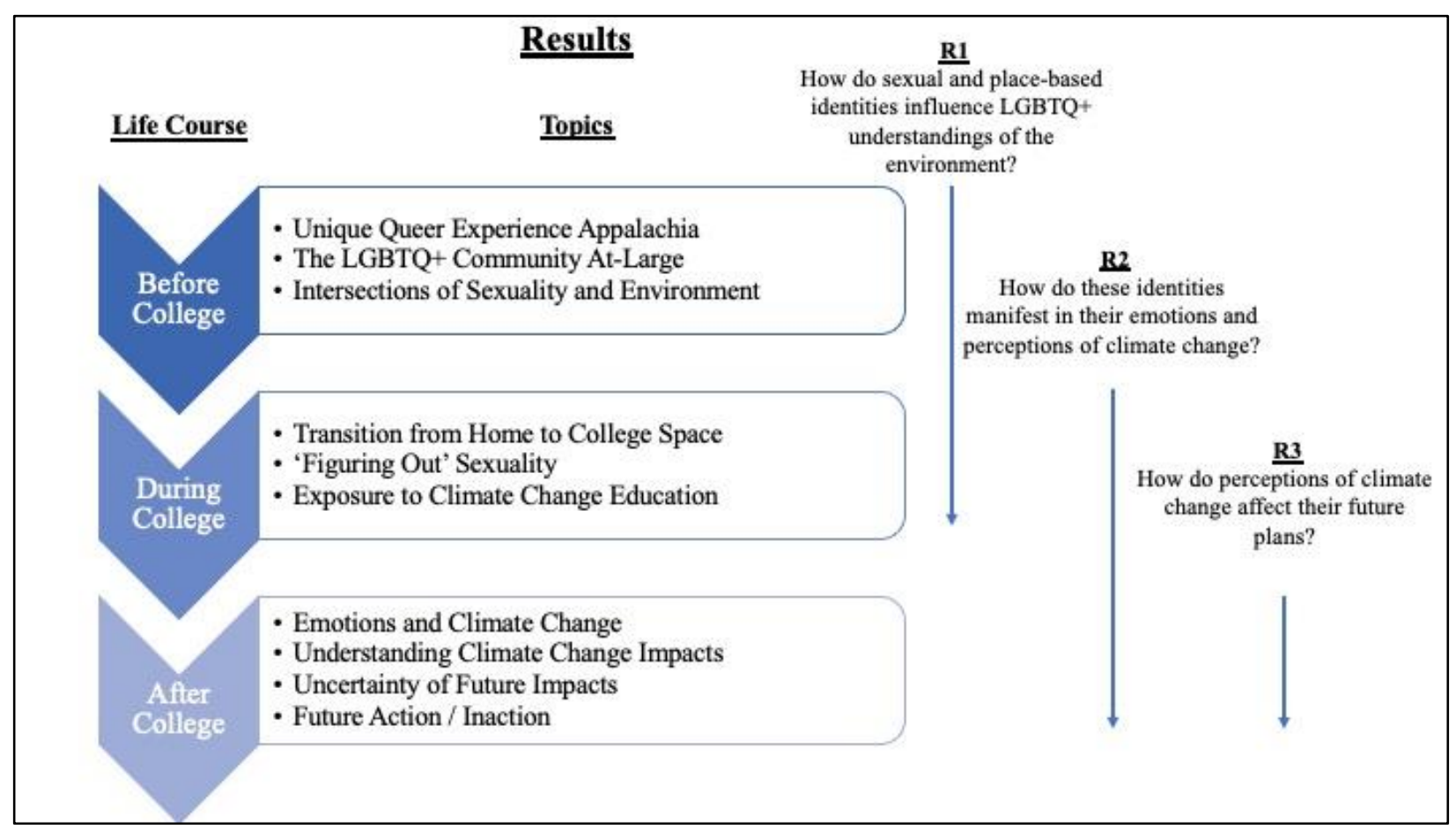

Figure 10: Life Course Approach to Understanding Results

\section{Before College: Sexual Identity Formation in Appalachia}

Participants' testimonies unanimously stressed that growing up in Appalachia produces unique queer experiences. The rurality of Appalachia, as well as its associated traditional and conservative cultural and social values, makes it difficult for Appalachian queers to connect with the mainstream LGBTQ+ community in urban centers such as New York City. There is often a flight of queer Appalachians to larger regional urban centers as a way to connect to this more mainstream community. The urban centers have more community visibility via celebrations such as Pride, while in Appalachia it is difficult for participants to visualize their community. The geographic disconnection from other LGBTQ+ individuals was felt by roughly half of the participants. Participants spoke to feelings of isolation they have from other LGBTQ+ people and spaces in Appalachia. The quote below illustrates a majority of participants' thoughts:

"I think more and more recently, people are trying to get behind this idea that if you're $L G B T$, there's this kind of metro-normativity. This 'you should move to the city and then just try to make it work there because that's better than wherever you come from. 'And I think that Appalachian LGBT people particularly have this kind of reaction. They feel isolated." Interview 3 
This participant believes that being LGBTQ+ instills a specific set of values or experiences that produce an affinity to urban or metropolitan spaces. The participant notes a heightened sense of metro-normativity, or the assumption that LGBTQ+ people cannot be normal or liberated in rural spaces, among Appalachian queers. This assumption, coupled with the isolation LGBTQ+ Appalachians experience in the everyday, drives them to believe that their life goal must be to move to a city to partake in 'normal' queer activities and embody a true sense of belonging to the queer community in the future. The participant notes that these metropolitan spaces are believed to be 'better than wherever you came from', showcasing how even if the participant were unfamiliar with urban spaces, it would be more beneficial for identity formation and overall personal growth to be in an urban space than in an Appalachian space.

Though isolation was felt by participants in Appalachian space, the LGBTQ+ community atlarge acts as a key component for queer identity formation. Queer identity for participants was discovered and constructed via entrance into the community. The community acts as a home for sexual and gender identities who fall outside constructed norms and broader heteronormativity evident in American society. With heteronormativity embedded within different spaces, such as the home, and within governmental structures and institutions, such as marriage, the LGBTQ+ community acts as a site of support for those who embody a shared lived experience of 'finding' their sexual and gender identity. This shared lived experience produces a sense of belonging for all participants. The following quote is representative of the majority of participants' thoughts on the journey of discovering their sexual and gender identity and being a part of the community:

“. . . it means just being part of a community of people who've had to sort of reconcile with a change. . . had to recognize that change within themselves. . and because of the heteronormative normative society most of us grew up in, being gay or just queer it just takes a sort of learning and discovering. . we have to sort of separate ourselves from the society we grew up in order to live truly to us. To me, that is one of the more central things that connects the LGBT community is that everybody who identifies in that community has had to go through some sort of personal journey to get there." Interview 26

In the quote above, the participant discusses how everyone in the LGBTQ+ community had to learn and discover their identity outside of the heteronormative society they grew up in. This process of discovery and learning is an event that separates LGBTQ+ people from broader 
society. Heterosexual people, the participate claims, do not have to reconcile with changes in their identity to be 'truly themselves'. This personal journey, which is emblematic of queer experience, binds together the community. The community as a whole was described by participants as being unifying, accepting, and open-minded.

Participating in outdoor activities with other queer people in Appalachia mirrors the sentiment interviewees had of the unity and camaraderie the LGBTQ+ community produces. All participants spoke to having a greater appreciation for the environment based on their sexual and gender identities. One participant spoke to stereotypes of gay people caring about the environment, which was a sentiment shared by a majority of other participants as well:

"I think I have a greater appreciation for it. And that might be because I play into stereotypes of gay people and people of the community just because I think it's a very $L G B T Q$ thing to just be appreciative of really small things and really simple things. Going on hikes and just being in nature." Interview 17

In this instance above, the interviewee is appreciative of small, simple activities in nature such as hiking, which transport her both mentally and physically away from society. The interviewee notions that their sense of appreciation for the environment is emblematic of the LGBTQ+ community at large. The interviewee also believes that going on hikes and being in nature as a queer person, and along with other queer people, produces different experiences than people who identify as heterosexual.

A majority of other participants had similar sentiments. The natural environment was characterized as a safe haven or a liberatory space for participants, both in individual interviews and focus groups. Since the natural environment is outside of everyday life, certain stressors and hardships for participants seem to disappear when they are in nature. For example, the space allows queer participants to be free of heteronormativity present in broader society and feel more in tune with their spiritual and queer identities. The below quote encapsulates this sentiment for a majority of participants:

"I think there is sort of a romanticism there with the wild and wonderful. . it's away from the street society rules, things like that, where you get to go have fun, go build your own path. And I think to a lot of LGBT people, that's enticing because it's freedom. More than that, I think LGBT people and other minorities care more about the environment 
because they know what it's like to be marginalized. They know what it's like to have something damaged, and to have something precious taken from you. It's like an innate empathy, you know? ” Interview 6

The participant above, who is from West Virginia, utilizes the state's motto as a way to characterize the romanticism queer people have with the natural environment. To her, natural spaces are seen as places of freedom from 'street society rules' which allow her to be less mindful of how her queer identity is being influenced and impacted by broader society. Due to LGBTQ+ people being a minority group and a marginalized population, the participant believes that this social position produces a greater care and appreciation for the environment.

Participants' sense of appreciation of the environment takes form through a greater awareness of environmental and social justice issues. A majority of interviewees spoke to having a greater awareness of all social issues because of their LGBTQ+ identity specifically. Participants all had rather progressive stances on a variety of issues, from Black Lives Matter to climate change, based on their marginalized social identity. Occupying an identity that sits outside the norm challenged participants to be not only more aware of their physical and environmental surroundings, but also more aware of social campaigns experienced by other groups: "I started off more as a very environmentally conscious person, even before I fully understood my own sexuality. A lot of the people that I hung out with were more progressive in the aspect of the environment, very conscious of climate change. It was something that was always talked about. But I definitely think even over time, just interacting with other queer people, that there tends to be a certain progressive viewpoint that carries over with that. . it starts with social issues, and then transfers to how those social issues also relate to environmental issues and how a lot of poor communities, which sometimes happens to have LGBT members, are affected by these terrible environmental conditions that end up making you care more about the issue itself." Interview 8

In the quote above, the participant thinks of themselves as an already environmentally conscious person due to growing up surrounded by more environmentally conscious peers and friends. Their understandings of the environment were developed prior to understandings of their own sexuality. A majority of other participants shared the same sentiment, noting that their understandings of the environment often became more progressive as they understood their sexuality. In this instance, the participant realizes that their environmental consciousness became 
elevated through their understandings of their own sexuality and through interactions with more queer people.

A majority of participants asserted that their queer identity encompasses a progressive viewpoint which allows them to visualize social issues that do not only affect queer people. For example, this participant speaks to instances of environmental racism and classism in which environmental issues are more prevalent in poor communities. These communities, as a majority of other participants pointed out, are often comprised of people of color. LGBTQ+ individuals based on their marginalized position within society may also experience environmental classism. These tangential experiences elevated the participant's progressive viewpoints, because they were aware of environmental issues that affect people in and outside of the LGBTQ+ community. The quote below by a focus group participant also draws connections to their own livelihood, as being LGBTQ+ is 'their life':

"I do think that identifying with the queer community forces you to think about these more progressive issues because that's your life. That's the people that you care about. The environmental movement is something that is a facet of the larger progressive movement. I think that subscribing to the progressive movement in general makes you more appreciative of the environment and of the issues we all deal with." Focus Group Participant 5

In the instance above, the interviewee realizes that her queer identity and her involvement with the LGBTQ+ community at-large force her to think about other progressive issues. Issues deemed progressive in nature, such as those concerning the environment, LGBTQ+ rights, and racism, were all noted by participants as being causes that they found their lives personally entangled in. By subscribing to a progressive stance, it forced participants to think about their own positionality in the world in relation to others, and to think about the various issues that occur in society, both inside and outside of the environment.

\section{During College: Changing Understanding of the Environment and Climate Change}

The transition from home to college is one in which participants' understandings of the environment were further articulated. As participants began taking courses in various majors, 
from industrial engineering to nursing, they became better informed of social issues that occur outside the university setting. Concurrently, participants began to experiment and understand their sexuality within the college setting. Roughly half of interviewees commented on how being surrounded by more queer people of similar age helped inform their own sexuality. For example, one participant commented on how prior to attending college, her parents told her to only focus on her academics since they did not have enough money to be able to pay for her education. Therefore, she believed that her sexual identity formation took a backseat to her academic pursuits. However, as she entered a college space and learned more about topics such as gender and sexuality in her coursework, she came to the realization that she was queer. The transition from home space to college space afforded her the knowledge to better understand her sexuality.

In similar instances, two other interviewees commented on how they were homophobic prior to coming out in college. One interviewee in particular noted how her conservative and traditional thoughts on LGBTQ+ people were influenced by her parents and by her rural town in Appalachia. As she moved to a larger, more progressive setting in college, she came to the realization that she was, in fact, lesbian. This act of 'figuring it out' was commented on by a majority of participants within a college setting. The more progressive nature of college campuses, participants noted, helped formulate their identities.

All participants spoke to the certain liberal-conservative and rural-urban dichotomies associated with college towns in Appalachia. College towns were essentialized as 'liberal bubbles' by participants, who understood that education at the university separated them from the rural, conservative and often less educated spaces outside the college town. Conservative values in Appalachia were equated to a perceived sense of homophobia and racism by participants. These values are therefore passed down from generation to generation. Those whose identities fall outside of the white, straight, cisgender accepted norm are effectively driven out of the space. The following quote exemplifies the perceived unwelcoming aura associated with Appalachian rural space:

"When I did go out into Christiansburg or more rural Blacksburg, there was just a lot of very evident racism. And I always associate that with homophobia and transphobia on the sidelines of that because if you're a bigot, you're gonna be a bigot pretty much across the board. So again, it's less subtle. I feel like if I had a non-passing trans friend and I 
went into the community, there's possibilities of things being said or done. So it's not like my identity's not completely clear and written out on my forehead or whatever, but there is definitely homophobia subtly under the water throughout that area. At least personally, from my perspective and my own experiences. "Interview 20

In the instance above, the interviewee comments on the outward racism on display within rural areas outside of her university. The interviewee associated racism with visible displays of Trump 2020 memorabilia and confederate flags. Homophobia and transphobia were then inferred via these displays of racism. The interviewee, who identified as bisexual, felt that they were able to make their sexual identity less visible and present as a cis-gender woman. To them, this ability to 'pass' would not be an option for someone who is transgender. Being able to 'pass' for the interviewee also affords a certain amount of safety and protection against bigotry and racist or homophobic attacks.

Within the focus groups, another participant spoke to the overt displays of racism within their hometown, and how these displays make them fortunate that they present as heteronormative: "So I live in a really rural area at home and it's also a really low-income area. It's all white. I've seen one person of color in my area, and they were forced out because they weren't white. They [the white residents] went so far as to attack the property they lived on and burned down trees. Anything they could do to get them to leave because they weren't white and they didn't meet the standards of the area. . I know my whiteness gives me privilege out there [in the environment], but at the same time, being queer makes me disadvantaged. It's really nice that I present heteronormative because I think that if I didn't and I went out back home, I would get a lot of harassment because of the way I identify." Focus Group Participant 1

In the quote above, the participant illustrates the interconnectedness between issues such as class, homophobia, and racism. Those who fit outside traditional, white values are driven out of Appalachian space. She is privileged, both in the sense that she is white and that she presents as heterosexual. Without these privileges, she assumes that she would meet a similar fate as the person of color who was harassed and driven out of town. These privileges in the everyday also carry over into environmental space, in which the participant explained that she had more access to nature through hiking trails and other activities. 
All participants, whether in individual interviews or in focus groups, spoke to the way in which white privilege influences access to nature, as race does not act as an impediment to natural spaces. Whiteness is a visible marker of identity that affords access. An overwhelmingly majority of participants identified as white and made connections to the privilege their skin tone holds. Particularly at the intersection of their queer identity, a majority realize that their white identity acts as a visible protection while in nature spaces. By being able to pass as heterosexual or present as cisgender, there is a certain guise of privilege that is evident. In the following representative quote, participants were able to pinpoint the intersection of race, sexuality and gender and the privilege embedded within the intersection:

"I think that in general, being white and being LGBTQ is very much safer and easier than a lot of the things that queer people of color have to go through. And specifically within the environment. . .I've done a little bit of reading about how people of color disproportionately visit natural places less so than white people do, or at least of what they've recorded of visitors and stuff like that. But I think that if you were a person of color and also queer and trying to inhabit these spaces, it might feel more challenging, and I think that I benefit from whiteness in the environment especially. Because I'm allowed to be places that certain people are not." Interview 3

For this participant, they understand that whiteness as privilege is able to transcend their queer identity within environmental spaces. There is a certain guise of unsafety that queer people of color experience within the environment as well. White people are normalized within nature spaces while people of color are viewed both as unwanted and uncommon. Through their college coursework, the participant is able to understand the intersection between race and sexual identity. They understand that queer people of color face more challenges in accessing natural environment spaces based on these intersecting identities, while they themselves, who are white and queer, do not have the same intersection.

Socioeconomic standing was also spoken about at length within both focus groups, mostly in the ability for people to indulge in sustainable practice, both on their college campus and in life more generally. For example, some participants mentioned how being vegan is environmentally friendly and a positive, sustainable practice to partake in to help mitigate climate change, yet veganism is often inaccessible to poorer communities. Vegan restaurants often carry more expensive foods and are located in more expensive areas. Not to mention, sustainable products such as reusable water bottles and other ethically sourced products are more expensive as well. 
These socioeconomic barriers to sustainability are further noticed by queer college students, as participants noted that their queer identity again keeps them more aware of intersecting issues of environmental and social justice.

\section{After College: Climate Change and the Future}

Knowledge of climate change and its associated impacts, both present and future, produced negative emotions in participants. Fear, worry, doom, dread, pessimism and other emotions with negative connotations were felt by all participants when speaking about climate change. Most participants developed a defeatist attitude based on their knowledge of climate change, and how climate change impacts will continue to worsen over the course of their lifetime. Interviewees were well aware of climate change-induced consequences for both nature and humans e.g. species loss, habitat loss, landmass loss, poverty, and multifaceted damage. Climate change is embedded in participants' daily lives through their college coursework, extracurricular activities, and jobs, and is a major topic of conversation among friend groups as well. In particular, the awareness of social issues brought on through LGBTQ+ identity elevates climate change as an important topic. Yet, constantly learning and talking about climate change within a college space also further produces negative emotional response. The instance below is representative of this conundrum:

"Climate change and other issues along those lines are like a train coming at me on the train tracks. It's inevitable, but I don't know what day it'll come because it's too far away on the horizon, but I can still hear it. And it's terrifying. I am exhausted every day waking up because I feel this overarching sense of dread, and when I try to talk to my parents about it or other people, they just chose to not delve into the issues. Which every day I think more and more as a smarter idea. They just tell me to relax about it, that I can't do anything about it and that just makes me feel worse." Focus Group Participant 11

In the quote above, the participant explains that their emotions associated with climate change were almost entirely negative. They believe that it would be better to not speak about the issue of climate change or learn about it further in their social science classes because not talking or learning about it would create less mental stress. The participant commented on how family members, who identify as conservative, disregard climate change. The participant also explained how their circle of friends, who they describe as leftists, have come to the conclusion that 'ignorance truly is bliss' as they are constantly bombarded with information about world issues 
within their college coursework. This constant barrage of information produces anxiety and negative emotions, such as dread. In the instance below, another participant speaks to how worry and anxiety about climate change is generational in context as well:

"It's definitely a topic that makes me feel worried, partially for me, but also partially for the kids and the younger kids in school now. Our generation and their generation are going to be seeing the effects of the mistakes of our past." Interview 28

In the instance above, the interviewee works as a camp counselor, a fly-fishing guide, and a recreation manager outside of attending university. He is a recreation, parks, and tourism management (RPTM) student that utilizes the forest as a living-learning environment. His RPTM and sustainable development coursework is directly embedded within the natural environment. When speaking about what emotions came to mind regarding climate change, he mentioned how the younger children who come to day camps that he helps run are becoming more aware and more worried about climate change. Children would go home after the camps and ask their parents to get recycling and composting bins in an effort to 'do something' about climate change and help the environment. When thinking about his own life, he is worried that his livelihood will be altered in the future, in the sense that fly-fishing season is changing and there are less fish populations to fish for. He also mentioned that he worries about his younger brother's life too, as they will both have to deal with climate change impacts brought on by inaction of generations prior.

Though all participants had elevated understandings of climate change via the educational avenues noted above, a majority could only think of events that were outside of their immediate geographic vicinity in Appalachia. Most often, climate change connections were made to changes noticed in the physical environment that were happening elsewhere geographically. Participants not being able to predict effects of climate change in their immediate environment is illustrated in the representative quote below:

"When I think of climate change, I think of the more extreme events that you see in the news, like more extreme weather patterns with hurricanes getting worse and more frequent every year, all the droughts in California and the wildfires in Australia... I think of those because I don't really have any first-hand experience with seeing effects of it. In my mind, I kind of go towards some more extreme, like rising ocean levels along the coasts, just because that's ultimately where it could end up on a bigger scale." Interview 7 
In the quote above, the participant is from rural West Virginia. Seeing extreme weather events on the news and on social media platforms such as Instagram prompted them to see extreme events happening 'elsewhere'. These extreme events serve as the participant's basis for how all climate change impacts in the environment occur and will occur. A majority of participants understood climate change as something that occurs elsewhere and asserted that climate change is of more concern in areas that are already seeing effects. For example, places such as New York City, California, and Florida were mentioned by most participants as areas threatened by climate change currently. These three areas were also mentioned by participants as places in which climate change impacts will be more severe in the future.

In tandem, over half of participants were clear on where they would not live as climate change impacts worsen in the future. Participants spoke again to geographic areas that they associated with extreme events, such as New York City, Florida and California, as locations that they would not relocate to after college. Wildfires and other environmental hazards were justifications for not moving to locations where climate change impacts are already understood as occurring. In the below representative quote, a participant speaks to the questions she asks herself as climate change impacts stay uncertain:

"It definitely might affect the places where I live. . it makes me be like, "I want to live in a bubble where environmental disasters can never hurt me." If you are moving somewhere like Florida, for example, which has a lot of hurricanes, and you live there knowing the risk of there being a hurricane that hits your house. . .am I willing to live in a spot where I could risk losing my home? ” Interview 4

Here, the interviewee is from West Virginia. She can identify climate change impacts 'out there', such as those that affect the state of Florida. She asks herself if she is willing to move to a location in the future that experiences hurricanes, as she has the education and knowledge that climate change will amplify those experiences. A majority of participants raised similar questions and spoke to their privilege in being able to make such judgements about their future.

Roughly half of participants believed that there are minimal links to concern of climate change in Appalachian regions. Participants thought that states in the Appalachian region, such as West Virginia and North Carolina, where they either lived or went to school do not 'see' immediate effects of climate change. Therefore, participants believed that concern of climate change 
amongst people in the areas outside of their college or university space is lessened. With less understanding of local impacts and accentuated lack of concern, participants believed that conservative viewpoints on climate change are amplified and therefore thought of as true by those who are less educated in Appalachia. Participants noted that climate change is 'proven' to be false by conservative family members and conservative media more broadly because 'it still snows,' or the temperature 'has only raised 1 degree'. If the effects are not extreme like those seen elsewhere, then other minimal effects are completely ignored or cast aside as one-off occurrences. For example, a handful of participants noted how older generations, such as their grandparents, would comment on environmental changes, such as how there was less snow than previous seasons, yet not equate these changes to climate change. These conservative viewpoints then produce a lack of care. In the quote below, a participant spoke to the lack of care they themselves could have due to the lack of visible impacts in West Virginia:

"West Virginia is not really at risk. I feel mixed about it because in all honesty, I think I could not care. I think I could just be like, "Oh, that's your problem, Florida. You'd all drown, that's your problem. It's your problem, Australia and Africa and China. You guys are the ones who are suffering." West Virginia has plenty of trees. It's a good environment, it's well sheltered from most natural disasters that are being amplified by climate change. We aren't necessarily impacted, and I'm not surprised that lots of the West Virginians, especially older ones, don't see or care because you can't really see the issues here." Interview 11

Here, the participant realizes that he could simply not care about climate change because climate change does not affect his immediate environment. However, because of his education on climate change, coupled with his queer identity and more progressive stance on environmental issues, he cares. The participant believes that a lack of care about climate change continues to be amplified within Appalachia. With his home state of West Virginia hypothesized to be a 'buffer zone' by mainstream climate change impacts and extreme events such as hurricanes, he believes that conservative family members and relatives will continue to believe that climate change is not occurring. Appalachia in general was assumed by half of the participants to be a future safe haven from climate change as impacts worsen elsewhere over time. A handful of other participants had similar thoughts that they too did not have to care about climate change, but because they are educated on the topic and understand its impacts on marginalized communities, they still do. 


\section{Uncertainty, Action, and Inaction}

As participants' knowledge of climate change often gravitates towards thinking about extreme impacts, this knowledge produces uncertainty of individualized impacts. As college students learn about climate change impacts, they become more concerned with how their livelihoods, from jobs and extracurriculars to their immediate environment, will be impacted in the future. Even with the knowledge of future climate change impacts, there is a heightened level of uncertainty among participants about how they will be able to act or react. The time after college graduation is already uncertain due to a plethora of overlapping issues: being able to afford rent, being able to find a job, and being able to become independent from parents or guardians. These uncertainties, all participants mentioned, are exacerbated as they think about climate change. In the representative quote below, a participant comments on the severity and extreme consequences of climate change:

"I guess climate change to me, if I can put it sort of metaphorically is like looking at a photograph of exactly where you are right now, but it looks nothing like where you are right now. It's this idea of progressing toward a future that isn't recognizable. And I think that that's what scares me the most about it is how little we can predict about what's going to happen, and how little we can predict about what our personal response is going to be to dramatic changes in our world. I mean, we could be talking about losing entire states, losing entire countries, losing species that are charismatic and talked about in the day-to-day vernacular of human society. And it's just a world that is difficult to recognize as the world that we live in now." Interview 10

In this instance, the participant describes climate change as an unrecognizable photograph. This photograph of the future is something that the participant cannot visualize himself. Despite being an ecology major and studying climate change impacts on tree species in Central Pennsylvania, as well as spending a majority of his academic and extracurricular time outdoors in a nearby forest, he does not believe that society will be able to predict what will happen. The interviewee went on to explain how climate change will produce cascading effects within the humanenvironment nexus. These effects across society will also influence his personal response to climate change. As places, states and countries become physically altered by climate change, he is unsure how his livelihood will truly be affected. In tandem, another participant spoke to how one event, graduating college and becoming an independent adult, will be altered by future uncertainty of climate change impacts: 
"My main concern is my inability to have a future and to experience life as an independent adult. I mean, obviously, you can do that in your later 20s after you graduate from undergrad, but what am I supposed to do in a dying world? As an 18 yearold what is my future going to look like? I'm not particular to a family or marriage, but are people who want that going to be able to achieve that? Is there going to be population control in force? How is our social existence going to change? How is society going to adjust to these massive changes and who is it going to affect the most? This is very eye opening to me. But as a whole, I'm very concerned with the possibility of having a future and growing up. " Interview 20

In the above quote the participant feels she will be unable to partake in a key life event. As the world dies, the participant realizes that her options are limited because the future is uncertain. She comments on how it may become more difficult for people to have children or to get married, and how social existence as a whole will be altered. In particular, she worries that those who are in marginalized positions, such as LGBTQ+ persons, will have uncertain futures, too.

In the above quotes, students are unable to think about their future in relation to climate change. Dramatic changes to the current human-environment system are inevitable, but the extent to which individuals will be affected varies across social identity markers and categories. The privileges associated with class, racial, and gender hierarchies in society at-large will produce inequitable effects as climate change worsens. Concern over not having children or other events that are a part of the quintessential imagery of 'growing up' was referenced by all participants.

Aside from individual concern for the future, participants felt overwhelmed by the high amount of inaction by corporations and their universities on climate change. Inaction on climate change produced emotions of anger, frustration, and anxiousness. All participants spoke to being incessantly told that their generation will be the one to 'solve' climate change and other societal issues. There is an internal struggle for participants, particularly because they are educated on societal issues and want to make a difference in some capacity. For participants educated on and interested in climate change, they are faced with the problem of wanting to make a difference in terms of buying habits and using reusable and more sustainable materials. Yet, participants realize that the difference they would make with these habits and changes is minimal. The quote below is representative of the emotions associated with this conundrum: 
"I think for the most part, it's really frustrating because the more I learn about stuff, the more overwhelming it becomes. I want to do my best to make a difference. I use my reusable bags and I have my metal straw. I do so much on the small scale in my everyday life to make myselffeel like I'm making a difference, but it's frustrating knowing that the cause of all of this is out of my hands and there's nothing I as an individual can do to make as big a difference as I want to." Interview 24

Participants believe that corporations, which produce most of the emissions that cause climate change, are abstained from blame. Blame is pushed onto the individual, yet participants are aware that the issue is larger than them. Collective action on a large-scale and stronger action from corporations would help address climate change issues. However, particularly in the focus groups, both groups spoke to their uncertainty that corporations and government entities will 'do the right thing.' For example, when speaking about the recent snowstorm which decimated entire counties and left millions without power, running water, and heat across Texas, participants directly stated that government entities did little to help. They also noted that Texas government officials refused to winterize the energy sources, and that the privatized energy grid overcharged customers and was unable to keep up with demand. The following quote extenuates growing concerns among participants that if drastic action is not taken immediately, their future becomes even more uncertain:

"I think it's just definitely an anxious thought. It's just a sense of urgency where if action isn't taken soon, big actions, then we're going to be in a lot more trouble than we're already in. ” Interview 21

Yet, as mentioned in the previous section regarding participants' acute awareness about privilege and access to the environment, participants also believed that their socioeconomic standing would place them at an individualized advantage as climate change progresses. Whiteness and socioeconomic privilege for participants combine and help mitigate the marginalized positionality their LGBTQ+ identity might produce in society. Climate change was assumed to not affect participants based on their LGBTQ+ identity alone, as the privilege associated with other intersecting identities outweighed the marginalization that is perceived to occur in the future. The quote below is representative of the majority of sentiments:

"I come from a fairly privileged and wealthy background, so I know that. . well, climate change is already creating impacts, but I know that those impacts are not going to reach me for a while. I know that I have a certain level of protection that others don't." Interview 21 
In the quote above, the participant knew that climate change impacts were occurring, and that they were impacting other people, both in the U.S. and abroad. Yet, their white privilege and their socioeconomic privilege act as a buffer to climate change impacts. These privileges will therefore 'buy her time' in the future. The participant had no worry that her LGBTQ+ identity would make her more prone to climate change impacts, both in the present and in the future. A majority of participants held similar views based on their identities as well. Their queer identity often took a backseat to other intersecting identities in broader conversations about climate change and the future.

\section{Discussion}

This thesis investigated how sexual and place-based identity formation of LGBTQ+ undergraduate students in Appalachia contributes to understandings of the environment and climate change.

The following discussion is separated into three parts with respect to the three research questions. The first part discusses sexual identity formation in Appalachia and its contribution to understandings of the environment, as well as the extractive legacies that produce unique place attachment. The second part discusses the manifestation of emotions and identity in understandings of climate change. The third part discusses perceptions of climate change and the uncertainty associated with future impacts.

Departing from feminist geography, queer geography, and emotional geography, this research contributes to intersectional academic studies at large by exploring how named identity categories such as class, race, sexuality, and gender influence understandings of the natural environment. Further, the research adds to studies of place-based attachment and emotions associated with change in one's immediate environment. The research also furthers the understanding of LGBTQ+ experience during disaster while offering a distinct, regional focus in Appalachia. 


\section{Sexual and Place-Based Identities and their Influence on Understandings of the Environment}

Interviewees highlighted that there are unique queer experiences in Appalachia that are outside of the mainstream LGBTQ+ movement. Traditional, conservative values which characterize the region play into the rural-urban divide, with queer Appalachians feeling isolated from urban centers where LGBTQ+ identity is more visible and widely accepted. These feelings of isolation often translate into participants believing there is an underlying necessity to relocate to the city center. Despite feelings of isolation, participants noted that being a part of the LGBTQ+ community at-large, no matter where they are located geographically, is a main driver of identity formation and acceptance. Interviewees commented on the lived experience that people who identify as LGBTQ+ share, such as unlearning heteronormative action and practice. A conjunction of Appalachian identity and queer identity helped produce a greater sense of appreciation for the natural environment. A majority of participants spoke to the way in which the natural environment acts as a safe haven: a place where they can 'escape' and 'be free' from the day-to-day struggles of being LGBTQ+.

This research contributes to feminist, geographical intersectional studies at the confluence of named identity categories such as race, gender, sexuality, and class in conjunction with the natural environment. The work of Finney (2014) and Shabazz (2015) in particular focus on representations of the environment and how such representations feed into stereotypes of who is engaged in the natural environment and who is not. Dominant narratives about the environment have been constructed through a white perspective, and these narratives are often deemed authentic and universal by mainstream society (Finney, 2014: 10). This denies the historical and contemporary complexity of experience for racially marginalized individuals who have experienced blatant racism in both urban and rural space (Shabazz, 2015).

Environmentalism is often defined from a white, middle class perspective, and environmental participation has an outward white face (Finney, 2014: 26). Representation is a clear site of struggle for African Americans and the construction of Black identity at-large, as whoever has representational authority (in this case, cis-gender, heterosexual, white men) has the ability to 
determine how stories get told and how individuals think about themselves in relation to others. Visual representations of nature remain largely focused on the Euro-American experience, prompting a lack of visible African American participation in mainstream environmental activity (Mitchell, 2011). There exists a "racialized outdoor leisure identity" in which outdoor enthusiasts are seen as strong, young, and white, which acts as exclusion for racially marginalized individuals (Martin, 2004: 514 in Finney, 2014: 27). The dominant narratives and existing representations of the environment are a reflection of national identity, environmental values, and history; these representations and their associated, physical environments such as National Parks can produce feelings of insecurity, exclusion, and fear for African Americans based upon historical events like slavery, Jim Crow laws, and segregation. As mentioned prior, it is important to note that an overwhelming majority of study participants identified as white. Therefore, their race seldom acted as a deterrent for their participation in outdoor activities.

In tandem, this research supports the work of Marino (2018) and Norgaard (2012) on class privilege and climate change. Marino (2018) speaks to the complexity associated with 'voluntary buyouts' of coastal land and houses due to climate change-induced sea level rise. In a discussion involving FEMA buyouts in New Jersey following Hurricane Sandy in 2012, Marino (2018) discusses the state utilization of federal monies to purchase repetitive flooding properties. Though such actions have been hailed by the federal government as bipartisan solutions for adaption to sea level rise, similar buyout programs in Alaska do not work based on the lack of ownership of land and housing by Indigenous coastal communities and a complex intersection of race and vulnerability as well (Marino, 2018: 12). Therefore, Marino (2018) argues that climate change policies such as buyouts need to be diversified to account for the adherent whiteness and classism embedded in home ownership. This thesis situates itself in her discussion via the intersection of race and class for participants, and how participants understand future vulnerability in conjunction with their LGBTQ+ identity. Not to mention, Norgaard's (2012) discussion on class privilege and climate change centers the stark differences of climate change impacts based on one's position within the Global North and Global South. Norgaard (2012) comments on how global capitalism continues to widen the material conditions that intersections of identity are embedded in; these conditions normalize those from the Global North consciously and unconsciously not talking about climate change impacts. Norgaard's (2012) work intersects 
this thesis via the cultural, political, and economic ways in which perceptions of climate change in the Global North are manufactured. With the regional focus of Appalachia, this thesis directly engages with Marino (2018) and Norgaard (2012) conceptualizations of environmental privilege with an adherent class focus.

This research also expands on the work of Barry (2021) at the intersection of queer identity and Appalachian identity. Queer participants expressed strong connections to the natural environment, yet this strong connection is complicated via the traditional culture of the region. Conservative ideologies associated with Appalachian culture prioritize and give power to heteronormative practice, further producing complications for queer Appalachians during their upbringing. A majority of participants spoke to the intolerant, homophobic and racist views they often encountered in Appalachian space either through upbringing or through attending college in Appalachia, which prompts them to want to move to more perceived tolerant spaces. LGBTQ+ emigration out of Appalachia, as Barry (2021) asserts, is often done in order to find community, acceptance, and representation.

Participants' notions of emigration out of Appalachia and perceived perceptions of metronormativity also mirror conservations in queer geography on queer space. Queer geographical studies often focus on queer experience in urban areas (Stone, 2018; Misgav and Johnston, 2014; Brown, 2012; Oswin, 2008; Gorman-Murray 2006; Knopp and Brown, 2003), as urban 'elements' such as neighborhoods, streets, bars, and nightclubs can be designated and coded as queer. This coding creates further visual acceptance of LGBTQ+ persons in urban space. Yet, as space more broadly is naturalized as heterosexual (Oswin, 2008), queer space is often theorized and conceptualized as dissident or in opposition (Cohen, 1997). The constructed heterosexualhomosexual binary stands to further 'other' queers, as the homosexual is idealized and conceptualized as a white, urban, upper-middle class gay man (Stone, 2018). This conceptualization helps produce a privileging of urban space and experience, where queer bodies, despite not fitting into the idealized queer, are expected to emigrate to urban places of perceived tolerance (Barry, 2021; Stone, 2018; Halberstam, 2005). Herring's (2010) concept of bicoastality, where queer work is centered on and valued in cities spaces such as New York and Los Angeles, bodes similarities to participant notions of wishing to move from Appalachia. The 
adherent focus on urban queer experience minimizes rural queer experience. This research, therefore, stands to complicate metro-normativity through its regional focus in Appalachia which is geographically distant from the coast. Further, it echoes Stone's (2018) call for future studies on LGBTQ+ life in rural areas.

\section{Emotion and Identity due to Climate Change}

All interviewees spoke to the negative emotions they associate with climate change, both as a phenomenon and as an associated response to climate knowledge. For participants, climate change is directly embedded in college coursework and is often a topic of discussion amongst peers and friends. The onslaught of discussions on climate change have oftentimes made participants want to shut out information on the issue, for it causes high mental stress while dealing with other day-to-day activities and stressors such as college coursework, job interviews, and societal happenings on campus and off (i.e. racially-motivated police shootings and Black Lives Matter protests). Based on such emotions, there is an overarching need amongst participants to 'do' something about climate change, whether it be individualized actions such as composting or recycling and/or demanding corporate action. Participants felt angered by the inaction of large-scale polluters such as corporations and were also angry that these same polluters place blame on individuals for climate change. These inactions are directly tied to the space of Appalachia for a majority of participants as well, as the region is directly tied to coal and other extractive histories. These coal histories further encapsulate the complicated intersections of Appalachian identity and queer identity as discussed in the results section.

This research is directly situated within broader discussions of climate literacy in the United States as well. Tools on climate literacy such as the Yale Climate Opinion Maps illustrate the necessity for better climate communication and education in the Appalachian region (Leiserowitz, 2006), with states such as West Virginia and Kentucky often having the lowest state-wide, adult perceptions (Howe et al., 2015). Further studies that assess college-aged perceptions of climate change, particularly as perceptions relate to political ideologies, is necessary (Plutzer et al., 2016). As it is understood that climate change will produce differentiated vulnerability across named identity categories such as gender, race, sexuality, and 
class (Sultana, 2014; Denton, 2002; Nelson et al., 2002), LGBTQ+ persons, who are often marginalized in the everyday, must be included in future policy discussions on climate change.

The research also contributes to emotional geography studies on sense of place and place-based identity and attachment. There is a plethora of studies that focus on a shift in human-environment interactions brought forth by climate change, and how such shifts produce emotional impacts (Galway, 2019; Cunsolo and Ellis, 2018; Doring, 2017; Devine-Wright, 2013; Willox et al., 2012). This research mirrors Galway (2019) and Devine-Wright (2013) by highlighting the way in which place-based attachment and identity are influenced by environmental change. Galway's (2019) qualitative investigation of place-based knowledge of residents of Thunder Bay, Canada showcases how complex social-ecological challenges like climate change are felt and understood via landscapes in the everyday. Participants noted their negative emotions associated with localized environmental change, and how such environmental changes directly intersected other social issues that plagued the community, such as widespread poverty and unemployment. Galway (2019) further suggests that perceptions of climate change, specifically at the confluence of climate change policy and action, are necessary areas of future study where tensions between resource-dependence and environmental policy are prevalent. This study therefore situates itself in this call via a regional focus in Appalachia.

Further, the research supports Devine-Wright's (2013) recommendation that place-based attachments and identities must be identified across scale, with particular attention to localized processes. These localized processes, Devine-Wright asserts, help to better frame global issues like climate change and mobilize communities to act. The research also directly echoes Cunsolo and Ellis' (2018) study on ecological grief, as participants felt a range of negative emotions via an understanding of how climate change impacts the environment through extreme events such as wildfires, sea-level rise, and hurricanes. Given the ruralness of Appalachia, participants felt that they had a heightened affinity to the natural environment. The intersection of emotions and place-based attachment are imbedded within the unique intersection of queer identity and Appalachian identity, as discussed in the previous section. 
Emotions are also directly embedded within the broader debate on climate change perceptions, skepticism, and denial in the United States. Like Hornsey et al. (2018) assert, participants were acutely aware of the stark political, ideological divide on climate change, with conservative family members or peers dismissing the issue as fake and unfounded. These perceptions are directly influenced by politics and further amplified via the space of Appalachia, for the coal legacies yield significant power over regional psyche (Bell and York, 2010). Historical and present-day extractive activities in Appalachia produce anti-environmentalist sentiment (Lewin, 2019), which are encased in negative emotions and further produce division on climate change. Despite decades of socioeconomic and environmental decline as a result of extractive industry, conservative ideologies prevail across the region (McCright and Dunlap, 2011). These conservative identity constructions stand in opposition to participants' queer identities, as an overwhelming majority of participants identified as having progressive political views based on their sexual identity and on their higher education. This research upholds the assertion by Nabi et al. (2018) that emotions can act as a frame for assessing future climate change impacts. Emotions can further elicit greater risk perception, motivate people to informs themselves of the issue, and better inform educational action on climate literacy.

\section{Future Uncertainty}

As college-aged participants elevated their understandings of climate change and their own sexuality via the space of their college campus, they became more aware of the future impacts of climate change across the human-environment nexus. Through linking coursework, research opportunities, and on-campus jobs to climate change concepts, participants were able to give examples of extreme events, from sea level rise to species die-offs, that climate change produces both in the present and in the future. Yet, a majority of the participants could not make connections to impacts in their immediate geographic environment in Appalachia, even though there is data that shows that climate change impacts occur in Appalachia (Fernandez and Zegre, 2019). Despite most participants growing up in the region, a majority spoke to events such as hurricanes or wildfires that they see occurring in the media in places such as New York City or California. Appalachia in this aspect was viewed by participants as having minimal climate change impacts, and, therefore, viewed as an area where there is lessened concern. As mentioned 
in the previous section, participants spoke to how conservative viewpoints by friends, family, and peers produces a lack of care.

A lack of care is further amplified via participants' uncertainty of individualized impacts of climate change post-college and into the future. It was clear that places such as New York City or California aforementioned would be places that participants would not live in the future, based on the assumption that the impacts seen in the everyday would worsen overtime. Uncertainty about the future was directly associated with students' intersecting identities. Foremost, whiteness and socioeconomic class privilege were two identities that all participants believed might mitigate the marginalization their LGBTQ+ identity might produce in conjunction with climate change. Climate change, therefore, was assumed by participants to not solely affect their LGBTQ+ identity, but rather an intersection of identity. Racial and class privilege were felt to 'buffer' impacts of climate change. The queer identities of participants were often less discussed while speaking about future uncertainty and vulnerability than other identity categories.

This research therefore directly contributes to studies on LGBTQ+ vulnerability during disasters. There are a multitude of studies that speak to the exacerbation of LGBTQ+ marginalization via disaster events (Hunter et al., 2018; Gaillard et al., 2017; Gorman-Murray et al., 2017; Yamashita et al., 2017; Stukes, 2014; D’Ooge, 2008). Gorman-Murray (2017) asserts that the negative mental health outcomes for LGBTQ+ persons are increasingly amplified during disaster, as these marginalized populations already experience higher fear, anxiety, and discrimination in the everyday. The intersection of climate change and emotions was spoken to at length by a majority of participants. Combined with high rates of homelessness and suicide amongst the LGBTQ+ population at-large, disaster events such as hurricanes or earthquakes exacerbate these prevalent issues across the community (Yamashita et al., 2017). The work of Yamashita et al. (2017) on disaster response after the 2011 earthquake in Japan showcases the intersections of LGBTQ+ identity and vulnerability via the lack of use of a gender-inclusive help hotline by LGBTQ+ community members. A lack of use highlights how despite government actions to help those who identify as gender and sexual minorities in the aftermath of the earthquake, LGBTQ+ persons were still frightened to use it based on the vulnerabilities associated with their queer lived experience in the everyday. 
The vignette at the beginning of this thesis detailing Sharli'ie's experience in the aftermath of Hurricane Katrina also directly highlights the intersection between race, class, gender, and sexuality participants spoke to throughout this research as well (Gary, 2011). Participants understood their sexual identity in relation to other identities such as race and class, and how an intersection of such identities produces differentiated capacities to deal with climate change impacts. As mentioned in a previous section, the majority of participants in this research identified as white or white passing. Though the participants understood the privilege their race and class had on 'buffering' them from climate change impacts, this does not negate the racialized impacts disasters have. Finney's (2014) work on the collective memory of Hurricane Katrina, for example, showcases how media constructs and represents disaster as a site of struggle for African Americans and their environment. The media coverage that followed Hurricane Katrina stigmatized an entire community of African Americans and produced both psychological and material consequences. Painting criminality and poverty as fixed qualities of blackness was further normalized via mainstream representations of persons sitting on flooded roofs, as well as boarded up buildings and spray-painted homes. Images from Katrina reinforced the racial unconscious that dictates everyday action, such as that of 'defenseless, poor black folks who will bear the brunt of nature' (Finney, 2014: 67). These representations then make it difficult for African Americans in mainstream environmental discourse and environmental spaces of thought to form individual identities not directly associated with narratives of environmental struggle and environmental racism. Euro-American attitudes of nature occupy the center of historical human-environment relations, which seek to remove man from nature and allow man to control nature. These attitudes again minimize marginalized viewpoints on environmental relationships and strip racialized individuals of their agency (Finney, 2014: 56).

However, this research does not evaluate LGBTQ+ vulnerability during disasters, but rather hypothesizes participant response to future climate change impacts. Studies of LGBTQ+ persons in relation to the environment are often about the built environment of health spaces (Nama et al., 2017; McClain et al., 2016), educational spaces (Gacita et al., 2017; Kull et al., 2016), and workspaces (Hur, 2019; Sheridan et al., 2017), therefore omitting LGBTQ+ identities and their association to the physical, natural environment. With an array of studies on LGBTQ+ persons in disaster, there are none which address the intersections presented by participants in this thesis. 
This research further echoes the sentiment by Moser (2010) that future geographical studies must incorporate an intersectional lens on the onset when engaging with the human dimensions of climate change. It is imperative that geographers engage with interdisciplinary endeavors on climate change, for our particular academic training offers us a 'geographic advantage' (Moser, 2010). The 'geographical advantage,' which Moser (2010) defines via conceptualizations of spatial variability, scale, and spatial and temporal analyses, allows for a better understanding of relationships cultivated via the human-environment nexus. These advantages are further carried over into interdisciplinary work, where geographers can contribute to growing literature on the human dimensions of climate change.

Overall, this discussion speaks to the results of the research as well as the connections between literature across topics such as: LGBTQ+ vulnerability and disasters; emotional geography studies of place-based attachment and emotions; and racial and class privilege in conjunction with understandings of the environment and climate change. In the following section, I conclude by summarizing research findings, highlighting study limitations, and offering thoughts on future geographical studies.

\section{Conclusion}

This research analyzed LGBTQ+ undergraduate student understandings of the environment and climate change via a focus on sexual and place-based identity. LGBTQ+ undergraduate students at large, public universities in the Appalachian region understand how named identity categories such as sexuality, gender, race, and class intersect and influence how climate change impacts, both present and future, are felt.

The findings highlight that LGBTQ+ undergraduate students in Appalachia possess unique identities regarding sexuality and place-based attachment. These unique identities further envelope experiences in and understandings of the environment. As they are exposed to concepts of climate change via their coursework, peers, and extracurricular activities on the college campus, they understand how other, adjacent issues such as racism and homophobia intersect outside the college space. Based on an increased awareness of social issues such as LGBTQ+ rights and police brutality, queer participants express negative emotions while thinking about 
climate change impacts. They understand that climate change will produce instability, vulnerability, and insecurity across varying identities, yet are unsure of localized and individualized impacts. While understanding that climate change will produce changes in the very social fabric of life as they know it, participants envelope defeatist attitudes and feel uncertain with what their futures might bring.

This research aligns with environmental and climate change-focused studies across feminist geography, queer geography, and emotional geography. The research expands on Barry's (2021) work at the intersection of Appalachian identity and LGBTQ+ identity via highlighting the complications such identities bring. The research also expands the work of Cunsolo and Ellis (2018), Diener and Hagen (2020), and Devine-Wright (2013) at the intersection of place-based attachment and emotions via a regionalized understanding of climate change. Further, it expands on the work of Gorman-Murray et al. (2017), Yamashita et al. (2017), and other queer geographers through providing experiences, opinions, and perceptions of LGBTQ+ persons outside of disaster vulnerability. Research findings overall complicate mainstream queer experience research by highlighting the experiences of rural queers. The research then attempts to address a gap at the intersection of geographical work on queer perceptions of climate change via the utilization of life course as an analytical tool.

A limitation faced while conducting research was the ongoing COVID-19 pandemic, as the pandemic forced interviews and focus groups to be conducted online via Zoom. However, the pandemic allowed for a case study expansion from solely West Virginia University to other universities in the Appalachian region as well. Other limitations to this research were the sample size and the sample demographic. Participants were gathered via formal avenues such as established committee contacts and LGBTQ+ centers, as well as through informal avenues such as social media. Two schools - The University of Tennessee, Knoxville and Ohio University were included within the case study and had been contacted via both formal and informal avenues. Yet, these avenues did not garner any participants. Not to mention, participants interested in being a part of interviews and focus groups from each of the universities included in this research overwhelmingly identified as white and white-passing. A lack of persons of color in 
this research may have influenced understandings of the environment amongst participants interviewed.

Future studies regarding the topic are necessary to better understand the intersection of LGBTQ+ identity, place-based attachment, and climate change, and how such an intersection influences both the perception of other societal issues and the construction of individual worldviews. A future comparative study of older LGBTQ+ Appalachians who embody a life course or stage different from LGBTQ+ undergraduate students would be useful, for it may better influence regional policy decisions on climate change. Such a study would assess how LGBTQ+ perceptions and emotions of climate change may change over time and space, particularly as climate change impacts increase in frequency and intensity into the future. 


\section{Appendix}

\section{Appendix A: Interview Guide}

Personal

1. Where are you from? What brought you to Morgantown?

2. What do you study at West Virginia University?

3. What led you to choose this profession / major?

4. Does this profession / major allow you to be in nature or the environment? In what capacity?

The Environment and LGBTQ+ Identity

5. How do you self-identify?

6. What does it mean to you to you to be a part of the LGBTQ+ community? What does it mean for you to be a part of the LGBTQ+ community in Appalachia specifically?

7. Do you think that your identity as an LGBTQ+ person affects the way you think about nature or the environment? What about your race?

8. Do you think that your identity as an LGBTQ+ person in Appalachia creates different experiences for you with nature or the environment in relation to your peers? What about your race?

9. Can you recall a time in which you had a different experience or felt a particular way about the environment than those who do not identify like you?

Climate Change

10. What do you think of when you think of climate change?

11. Are these thoughts at the forefront of your daily life?

12. What does climate change 'look like' to you? Do you think this view differs from others who live in West Virginia and Appalachia more broadly? What about people in the country outside Appalachia?

13. How does this view or picture of climate change make you feel?

14. Do you feel more at risk to climate change impacts based on your identities? If yes, what are some sources of risk?

Climate Change and Place-Based Attachment

15. How might climate change impact where you live, work and play? What concerns do you have with climate change impacts in the future affecting you personally?

16. How does climate change contribute to your experiences living in West Virginia and attending West Virginia University? How do these experiences make you feel?

17. What do you think the University could do to address climate change impacts? 


\section{Appendix B: Focus Group Questions}

Intersection of LGBTQ+ Identity and Environment

"I would say I started off more as a very environmentally conscious person. Even before I fully understood my own sexuality, a lot of the people that I hung out with were more progressive in the aspect of the environment, very conscious of climate change, it was something that was always talked about. But I definitely think even over time just interacting with other queer people, that there tends to be a certain progressive viewpoint that carries over with that. . it starts with social issues, and then transfers to how those social issues also relate to environmental issues and how a lot of poor communities, which sometimes happens to have $L G B T$ members, are affected by these terrible environmental conditions that end up making you care more about the issue itself." Interview 8

"I think I have a greater appreciation for it. And that might be because I play into stereotypes of gay people and people of the community just because I think it's a very LGBTQ thing to just be appreciative of really small things and really simple things. Going on hikes and just being in nature." Interview 17

1. How does your LGBTQ+ identity intersect your love for the environment? Do you care for more progressive issues because of your LGBTQ+ identity?

Emotions about Climate Change

"I think it's just definitely an anxious thought. It's just a sense of urgency where if action isn't taken soon, big actions, then we're going to be in a lot more trouble than we're already in." Interview 21

"It's definitely a topic that makes me feel worried, partially for me, but also partially for the kids and the younger kids in school now. Our generation and their generation are going to be seeing the effects of the mistakes of our past." Interview 28

"I am pretty angry or frustrated. I'm hopeless. I'm pessimistic. Pretty much optimistic is the least likely word that would ever come to my mind when talking about climate change. Which is sad, because we need to have hope and we need to be optimistic. But it's very hard when I feel I'm aware..." Interview 15

2. Do you agree / disagree with the above quotes? Explain why or why not. Do you mostly have negative emotions associated with climate change?

Climate Denial in Appalachia

"I think that a lot of people, especially in southern West Virginia, have been so indoctrinated and kind of brainwashed by big industries here. Or they can't see another option because their livelihoods are dependent on these industries and they're not being given a good solution to removing the coal industry. They're so dependent on all these aspects that they'll just go to clean 
coal and think that that's the solution because it gets them to keep their jobs. And for most people, it's putting food on the table for their families, and they'll sacrifice all the health aspects that the industry is causing them." Interview 4

"A lot of times, I think being from Appalachia is associated with exploitation, too. It does seem like it's the story of being from Appalachia of people coming in and taking. In the past, it was taking profit out of the state. And then in my eyes now, it's taking jobs away from people, it's destroying the environment that people are living in, by big companies that don't particularly care whether the people profit." Interview 8

3. Do you agree / disagree with the above quotes? Why or why not. Where does climate change denial stem from in Appalachia?

Privilege in the Environment; Climate Change Impacts

"I think that in general, being white and being LGBTQ is very, very much safer and easier than a lot of the things that queer people of color have to go through. And specifically within the environment. . I've done a little bit of reading about how people of color disproportionately visit natural places less so than white people do, or at least of what they've recorded of visitors and stuff like that. But I think that if you were a person of color and also queer and trying to inhabit these spaces, it might feel more challenging, and I think that I benefit from whiteness in the environment especially. Because I'm allowed to be places that certain people are not." Interview 3

"I come from a fairly privileged and wealthy background, so I know that. . well, climate change is already creating impacts, but I know that those impacts are not going to reach me for a while. I know that I have a certain level of protection that others don't." Interview 21

4. Do you agree / disagree with the above quotes? Why or why not. How do you think your sexual, gender, racial, geographical, and class identities inform your understandings of climate change and the environment?

\section{Future Climate Change Impacts}

"I guess climate change to me, if I can put it sort of metaphorically, is like looking at a photograph of exactly where you are right now, but it looks nothing like where you are right now. It's this idea of progressing toward a future that isn't recognizable. And I think that that's what scares me the most about it is how little we can predict about what's going to happen, and how little we can predict about what our personal response is going to be to dramatic changes in our world. ” Interview 10

"We [Appalachia] are one of the few places that still has an intact functioning ecosystem, and that gives us some advantages towards climate change and facing the future. I do worry about the eventuality that a bunch of people are gonna want to live here because it's the only nice place left, but I'll definitely be staying here." Interview 28 
5. Has climate change given you uncertainty about the future? How do you foresee the future of Appalachia in relation to climate change? Give an example. 


\section{Appendix C: IRB Approval}

To: Martina Caretta

From: WVU Human Research Protection Program

Protocol Type: Exempt Submission Type: Renewal Funding: N/A

$09 / 14 / 2020$

Approval Date: 09/14/2020 Expiration Date: 09/13/2023

\section{Approval of Protocol Renewal}

WVU Protocol \#: 1709756670R001

Protocol Title: Exploring LGBTQ+ student attitudes and beliefs to climate change

The West Virginia University Institutional Review Board has reviewed and granted your request for reapproval of Exempt protocol 1709756670R001, in accordance with the Federal regulations 45 CFR 46, 21 CFR 50, and 21 CFR 56 (when applicable). Additional details concerning the review are below:

- This research study was granted an exemption because the Research involves educational tests, survey procedures, interview procedures or observation of public behavior and (i) information obtained is recorded in such a manner that human subjects cannot be identified, directly or through identifiers linked to the subjects; and (ii) any disclosure of the human subjects responses outside the research could not reasonably place the subjects at risk of criminal or civil liability or be damaging to the subjects financial standing, employability, or reputation [45 CFR 46.101(2)]. All exemptions are only good for three years. If this research extends more than three years beyond the approved date, then the researcher will have to request another exemption. The following documents have been acknowledged for use in this study and are available in the WVU+kc system:

- This research study was granted an exemption because the Research involves educational tests, survey procedures, interview procedures or observation of public behavior and (i) information obtained is recorded in such a manner that human subjects cannot be identified, directly or through identifiers linked to the subjects; and (ii) any disclosure of the human subjects responses outside the research could not reasonably place the subjects at risk of criminal or civil liability or be damaging to the subjects financial standing, employability, or reputation [45 CFR 46.101(2)]. All exemptions are only good for three years. If this research extends more than three years beyond the approved date, then the researcher will have to request another exemption. The following documents have been acknowledged for use in this study and are available in the WVU+kc system:

The following documents were reviewed and approved for use as part of this submission. Only the documents listed below may be used in the research. Please access and print the files in the Notes \& Attachments section of your approved protocol.

- Students' CC attitudes and beliefs_Interview Q_BR.doc

- SampleAd_BR.pdf

-WVU IRB cover letter--Student CC attitudes_BR.pdf

- Climate Change Knowledge Test and Attitude Survey_2020_BR.docx 


\section{WVU IRB approval of protocol 1709756670R001 will expire on 09/13/2023.}

Once you begin your human subjects research, the following regulations apply:

1. Unanticipated, serious adverse events and/or side effect(s) encountered at WVU or an affiliate site that are related to the research must be reported to the WVU IRB within five (5) days using the Notify IRB action in WVU+kc.

2. Any Unanticipated Problem or UPIRTSO or other research related event resulting in new or increased risk of harm to study subjects, occurring at WVU or an affiliate site, must be reported to the WVU IRB within five (5) days using the Notify IRB action in WVU+kc.

3. Any modifications to the protocol or informed consent form must be reviewed and approved by the IRB prior

to implementation. These modifications should be submitted as an amendment.

4. You may not use a modified informed consent form until it has been reviewed and approved by the WVU

\section{IRB. Only consent forms with the WVU+kc watermark may be used to obtain informed consent from participants.}

The WVU Human Research Protection Program will be glad to provide assistance to you throughout the research process. Please feel free to contact us by phone at 304.293 .7073 or by email at IRB@mail.wvu.edu.

Sincerely,

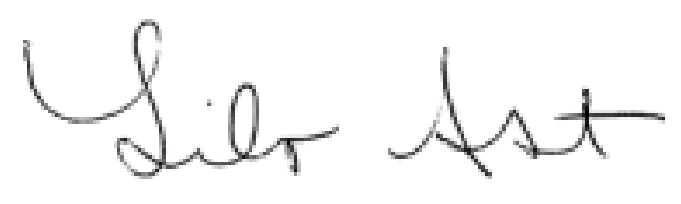

Lile Ast

IRB Administrator

Protocol \#: 1709756670R001 FWA: 00005078

Phone: 304-293-7073 Fax: 304-293-3098 


\section{References}

Albrecht, G. (2005). Solastalgia. A new concept in health and identity. PAN: Philosophy Activism Nature, 3: 41-55.

Albrecht, G., G. M. Sartore, L. Connor, N. Higginbothan, S. Freeman, B. Kelly, H. Stain, A. Tonna, \& G. Pollard. (2007). Solastalgia: the distress caused by environmental change. Australian Psychiatry, 15: 1-4, DOI: 10.1080/10398560701701288

Allen, M.R., O.P. Dube, W. Solecki, F. Aragón-Durand, W. Cramer, S. Humphreys, M. Kainuma, J. Kala, N. Mahowald, Y. Mulugetta, R. Perez, M. Wairiu, and K. Zickfeld. (2018). 2018: Framing and Context. In: Global Warming of $1.5^{\circ}$ C. An IPCC Special Report on the impacts of global warming of $1.5^{\circ} \mathrm{C}$ above pre-industrial levels and related global greenhouse gas emission pathways, in the context of strengthening the global response to the threat of climate change, sustainable development, and efforts to eradicate poverty [Masson-Delmotte, V., P. Zhai, H.-O. Pörtner, D. Roberts, J. Skea, P.R. Shukla, A. Pirani, W. Moufouma-Okia, C. Péan, R. Pidcock, S. Connors, J.B.R. Matthews, Y. Chen, X. Zhou, M.I. Gomis, E. Lonnoy, T. Maycock, M. Tignor, and T. Waterfield (eds.)].

Appalachian Regional Commission. (2009). Subregions in Appalachia. Accessed May 6, 2021 via https://www.arc.gov/map/subregions-in-appalachia/

Anshelm, J., and Hultman, M. (2014). A green fatwa? Climate Change as a threat to masculinity of industrial modernity. NORMA: International Journal for Masculinity Studies, 9(2): 8496.

Archibald, M., R. C. Ambagtsheer, M. G. Casey, and M. Lawless. (2019). Using zoom videoconferencing for qualitative data collection: perceptions and experiences of researchers and participants. International Journal Qualitative Methods, 18.

Barcus, H. R., and Brunn, S. D. (2010). Place elasticity: Exploring a new conceptualization of mobility and place attachment in rural America. Geografiska Annaler Series B Human Geography, 92(4): 281-295.

Baron, R. S., Logan, H., Lilly, J., Inman, M. L., and Brennan, M. (1994). Negative emotion and message processing. Journal Experimental Social Psychology, 30: 181-201. DOI:10.1006/jesp.1994.1009

Barry, J. M. (2021). Misfits in the Mountains: Tensions between Environmental and LGBTQIA Identities in Appalachia. Environmental History, 26: 39-45.

Baxter, J. and J. Eyles. (1997). Evaluating qualitative research in social geography: establishing 'rigor' in interview analysis. Transactions of the British Geographers, 22(4), 505-525.

Bell, S. E., and York, R. (2010). Community Economic Identity: The Coal Industry and Ideological Construction in West Virginia. Rural Sociology, 75(1): 111-143.

Binnie, J. (1997). Coming out of geography: towards a queer epistemology? Environment and Planning: Society and Space, 15: 223-237.

Bolsen, T., Druckman, J. N., and Lomax Cook, F. (2015). Citizens', Scientists', and Policy Advisors' Beliefs about Global Warming. Annals, AAPSS, 658: 271-295.

Bolsen, T., and Shapiro, M. A. (2017). The US News Media, Polarization on Climate Change, and Pathways to Effective Communication. Environmental Communication, 12(2): 149163. 
Bolsen, T., and Druckman, J. N. (2018). Do Partisanship and politicization undermine the impact of a scientific consensus message about climate change? Group Processes \& Intergroup Relations, 21(3): 389-402.

Brown, G. (2012). Homonormativity: A metropolitan concept that denigrates “ordinary" gay lives. Journal of Homosexuality, 59(7), 1065-1072.

Brown, M. (2000). Closet space: Geographies of metaphor from the body to the globe. Psychology Press.

Butler, J. (1993). Imitation and Gender Subordination. In H. Abelove, M.A. Barale, and D.M. Halperin (Eds.), The Lesbian and Gay Studies Reader (pp. 307-320). New York: Routledge.

Caretta, M. A. (2016). Member checking: A feminist participatory analysis of the use of preliminary results pamphlets in cross-cultural, cross-language research. Qualitative Research, 16(3), 305-318.

Chalfant, B. A. and Corrigan, C. C. (2018). "Governing Unconventional Oil and Gas Extraction: The Case of Pennsylvania." Review of Policy Research e0001. https://doi.org/10.1111/ropr.12319.

Cho, J. and Trent, A. (2006). Validity in qualitative research revisited. Qualitative Research, 6(3): 319-340.

Cho, Y. (2011). Intercoder Reliability. In Lavrakas (Ed.), Encyclopedia of Survey Research Methods (pp. 1-3). SAGE Publications.

Cohen, C. J. (2005). Punks, bulldaggers, and welfare queens: The radical potential of queer politics. Black queer studies, 21-51. Duke University Press.

Cope, M., and Kurtz, H. (2016). Organizing, Coding and Analyzing Qualitative Data. In Clifford et al., Key Methods in Geography (pp. 647-664). SAGE Publications.

Crenshaw, K. (1989). Demarginalizing the Intersection of Race and Sex: A Black Feminist Critique of Antidiscrimination Doctrine, Feminist Theory, and Antiracist Politics. University of Chicago Legal Forum; Vol. 1989, 1(8).

Creswell, J. W., and Creswell, J. D. (2018). Research design: Qualitative, quantitative, and mixed methods approaches. SAGE Publications.

Cunsolo, A. and Ellis, N. R. (2018). Ecological grief as a mental health response to climate change-related loss. National Climate Change, 8(4): 275-281.

Curtis, S., Gesler, W., Smith, G. and Washburn, S. (2000). Approaches to sampling and case selection in qualitative research: examples in the geography of health. Social Science and Medicine, 50(7-8): 1001-1014.

Denton, F. (2002). Climate change vulnerability, impacts, and adaptation: Why does gender matter? Gender \& Development, 10(2): 10-20.

Devine-Wright, P. (2013). Think global, act local? The relevance of place attachments and place identities in a climate changed world, Global Environmental Change, 23: 61-69.

Diener, A., and J. Hagen. (2020). Geographies of place attachment: A place-based model of materiality, performance, and narration. Geographical Review, 1-16.

Dominey-Howes, D., Gorman-Murray, A., and McKinnon, D. (2014). Queering Disasters: On the need to account for LGBTI experiences in natural disaster contexts. Gender, Place and Culture, 21(7): 905-918.

Domosh, M. (1991). Toward a feminist historiography of geography. In P. K. Moss (Ed.), Feminist Geography and Practice. Blackwell, Oxford. 
Domosh, M., and Seager, J. (2001). Home. In Putting Women in Place: Feminist Geographers Make Sense of the World. M. Domosh \& J. Seager (Eds.). Guilford Press, New York.

D’Ooge, C. (2008). "Queer Katrina: Gender and Sexual Orientation Matters in the Aftermath of the Disaster." In B. Willinger (Ed.), Katrina and the Women of New Orleans (pp. 2224). New Orleans, LA: Newcomb College Centre for Research on Women - Tulane University.

Doring, M. and Ratter, B. (2017). The regional framing of climate change: towards a place-based perspective on regional climate change perception in North Frisia. Journal of Coastal Conservation, 22(1): 131-143.

Elder, G. H., M. K. Johnson, and R. Crosnoe. (2003). The emergence and development of life course theory. In J. T. Mortimer and M. J. Shanahan (Eds.), Handbook of the life course (pp. 3-19). Kluwer Academic.

Eller, Ronald. (2013). Uneven ground: Appalachia since 1945. Lexington: University Kentucky Press.

Elwood, S. (2010). Mixed Methods: Thinking, Doing, and Asking in Multiple Ways. In DeLyser, D., Herbert, H., Aitken, S., Crang, M. \& McDowell, L. (Eds)., SAGE Handbook of Qualitative Geography (pp. 94-114). SAGE Publications Ltd: London.

England, K. (1994). Getting personal: Reflexivity, positionality and feminist research. The Professional Geographer, 46(1).

England, K. (2005). Producing Feminist Geographies: Theory, Methodologies and Research Strategies. In S. Aitken and G. Valentine (Eds.), Approaches to Human Geography: Philosophies, Theories, People and Practices (2nd Ed.) Sage Publications: London.

Eyles, J. and Smith, D. (1988). Qualitative methods in human geography. Cambridge: Polity.

Fabricant, N. (2015). Resource Wars: An On The Ground Understanding of Mountain Top Removal Coal Mining in Appalachia, West Virginia. Radical Teacher, 102: 8-16.

Fernandez, R., and Zegre, N. P. (2019). Seasonal changes in water and energy balances over the Appalachian Region and beyond throughout the twenty-first century. Journal of Applied Meteorology and Climatology, 58(5): 1079-1102.

Finney, C. (2014). Black Faces, White Spaces: Reimagining the relationship of African Americans to the great outdoors. UNC Press Books.

Flynn, J., Slovic, P., and Mertz, C. K. (1994). Gender, race, and perception of environmental health risks. Risk Analysis, 14(6), 1101-1108.

Fresque-Baxter, J. A. and Armitage, D. (2012). Place identity and climate change adaption: a synthesis and framework for understanding” WIRES: Climate Change, 3(3): 251-266.

Gacita, A., Gargus, E., Uchida, T., Garcia, P., Macken, M., Seul, L., and Wayne, D. B. (2017). Introduction to Safe Space Training: Interactive Module for Promoting a Safe Space Learning Environment for LGBT Medical Students. MedEdPORTAL: the journal of teaching and learning resources, 13.

Gaillard, J. C., Gorman-Murray, A., and Fordham, M. (2017). Sexual and gender minorities in disaster, Gender, Place \& Culture, 24(1): 18-26.

Galway, L. P. (2019). Perceptions of climate change in Thunder Bay, Ontario: towards a placebased understanding. Local Environment, 24(1): 68-88.

Gaventa, John. (2019). Power and powerlessness in an Appalachian Valley. The Journal of Peasant Studies, 46(3): 440-456.

Gecas, V. (2003). Self-agency and the life course. In J. T. Mortimer and M. Shanahan (Eds.), Handbook of the life course (pp. 369-388). Kluwer Academic. 
Gelbspan, R. (2004). Boiling point: How politicians, big oil and coal, journalists, and activists have fueled the climate crisis - and what we can do to avert disaster. New York: Basic Books.

Goldsmith, L. et al. (Forthcoming). Queer and Present Danger: Understanding the disparate impacts of disasters on LGBTQ+ communities. Disasters.

Gorman-Murray, A. (2006). Gay and Lesbian Couples at Home: Identity Work in Domestic Space. Home Cultures, 3(2): 145-147.

Gorman-Murray, A., Morris, S., Keppel, J., McKinnon, S., and Dominey-Howes, D. (2017). Problems and possibilities on the margins: LGBT experiences in the 2011 Queensland floods, Gender, Place \& Culture, 24(1): 37-51.

Grasso, M. (2019). Oily politics: A critical assessment of the oil and gas industry's contribution to climate change. Energy Research \& Social Science, 50: 106-115.

Gray, L. (2011, August 12). Transgender evacuee survives all obstacles. Houston Chronicle. Accessed April 18, 2021 via https://www.chron.com/news/hurricanes/article/Transgender-evacuee-survives-allobstacles-1931933.php

Halberstam, J. (2005). In a queer time and place: Transgender bodies, subcultural lives. New York: NYU Press.

Handcock, M. S., and Gile, K. J. (2011). On the concept of snowball sampling. Cornell University Library.

Hanson, S., and Pratt, G. J. (1995). Gender, Work, and Space, Routledge: New York.

Haraway, D. J. (1988). Situated knowledges: The science question in feminism and the privilege of partial perspective. Feminist Studies, 14(3): 575-599.

Hartsock, N. (2003). The feminist standpoint: Toward a specifically feminist historical materialism. Feminist theory reader: Local and global perspectives, 292-307.

Hawkesworth, M. E. (2006). Feminist Inquiry: From Political Conviction to Methodological Innovation. Rutgers University Press.

Hmielowski, J. D., Feldman, L., Myers, T. A., Leiserowitz, A., and Maibach, E. (2014). An attack on science? Media use, trust in scientists, and perceptions of global warming. Public Understanding of Science, 23(7): 866-883.

Herring, S. (2010). Another country: Queer anti-urbanism. New York: NYU Press.

Hoffmeyer, A. T., and Scott, C. M. (2000). Moral geography of focus groups with participants with preexisting relationships in the workplace. International Journal of Qualitative Methods, 6(2): 69-79.

hooks, b. (1991). "Homeplace (a site of resistance)." Yearning: race, gender, and cultural politics. London: Turnaround.

Hopkins, P. E. (2007). Thinking critically and creatively about focus groups. Area, 39(4): 528535.

Hopkins, P. E. (2017). Social Geography I: Intersectionality. Progress in Human Geography, 111. DOI: $10.1177 / 0309132517743677$

Howe, P., Mildenberger, M., Marlon, J., and Leiserowitz, A. (2015). Geographic variation in opinions on climate change at state and local scales in the USA. Nature Climate Change, 5: 596-603.

Hornsey, M., Harris, E. A., and Fielding, K. S. (2018). Relationships among conspiratorial beliefs, conservatism and climate skepticism across nations. Nature Climate Change, DOI: $10.1038 / \mathrm{s} 41558-018-0157-2$. 
Hughes, B. E., and Hurtado, S. (2018). Thinking about sexual orientation: College experiences that predict identity salience. Journal of College Student Development, 59(3), 309-326.

Hunter, L. A., Bagal III, G. R., Battle, J., Bewkes, F. J., Buchert, S., Hanley, T., Maury, M., McGovern, A., Morimoto, T., Sutherland, C., and Vaid, U. (2018). Intersecting Injustice: A national call to action, addressing LGBTQ poverty and economic justice for all. Social Justice Sexuality Project, Graduate Center, City University of New York. Accessed May 6, 2021 via https://socialjusticesexuality.com/files/2018/04/Poverty-Reports-ExecSummary.pdf

Hur, H. (2019). The role of inclusive work environment practices in promoting LGBT employee job satisfaction and commitment. Public Money \& Management, 1-11.

Hurtado, S., Alvarez, C. L., Guillermo-Wann, C., Cueller, M. and Arellano, L. (2012). A model for diverse learning environments. In J. C. Smart and M. B. Paulsen (Eds.), Higher education: Handbook theory and research (Vol. 27, pp. 41-122). New York, NY: Springer.

Johnston, L. (2003). Surveying Sexualities. In Ogborn, M., Blunt, A., Gruffudd, P., Pinder, D., \& May, J. (Eds)., Cultural Geography in Practice (pp. 122-138), Routledge: London.

Knopp, L. (2007). On the Relationship Between Queer and Feminist Geographies. The Professional Geographer, 59(1), 47-55.

Knopp, L., and Brown, M. (2003). Queer diffusions. Environment and Planning D: Society and Space, 21(4): 409-424.

Koelsch, L. E. (2013). Reconceptualizing the Member Check Interview. International Journal of Qualitative Methods, 168-179.

Kull, R. M., Greytak, E. A., Kosciw, J. G., and Villenas, C. (2016). Effectiveness of school district antibullying policies in improving LGBT youths' school climate. Psychology of Sexual Orientation and Gender Diversity, 3(4), 407.

Lahsen, M. (2005). Technocracy, democracy, and US climate politics: The need for demarcations. Science, Technology \& Human Values, 30(1), 137-169. doi:10.1177/0162243904270710

Lave, R., Biermann, C., and Lane, S.N. (2018). Introducing critical physical geography. In Lave, R., Biermann, C., Lane, S. (Eds.), The Palgave Handbook of Critical Physical Geography (pp. 3-21). Palgrave MacMillian.

Leggett, J. (2001). The carbon war: Global warming and the end of the oil era. London: Routledge.

Leichenko, R., and O'Brien, K. (2020). Teaching climate change in the Anthropocene: An integrative approach. Anthropocene, 30.

Leiserowitz, A. (2006). Climate change risk perception and policy preferences: the role of affect, imagery, and values. Climate Change, 77: 45-72. DOI:10.1007/s10584-006-9059-9

Lewin, P. (2019). "Coal is not just a job, it's a way of life": The cultural politics of coal production in Central Appalachia." Social Problems, 66(1). DOI: 10,1093/socpro/spx030

Lewis, P. F. (1979). Defining a sense of place. The Southern Quarterly, the University of Southern Mississippi, 17 (3\&4): 24-46.

Lincoln, Y. S., and Guba, E. G. (1985). Naturalistic Inquiry. Newbury Park, CA: SAGE Publications.

Longhurst, R. (1995). Viewpoint: The Body and Geography. Gender, Place, and Culture, 2 (1): 97-106. 
Mabry, L. (2012). Case Study in Social Research. In Alasuutari, P., Bickman, L., \& Brannen, J. (Eds)., SAGE Handbook of Social Research Methods (pp. 214-277), SAGE Publications Ltd: London.

Mani, L. (1990). Multiple mediations: Feminist scholarship in the age of multinational reception. Feminist Review, 35(1): 24-41.

Marino, E. (2018). Adaption privilege and voluntary buyouts: Perspectives on ethnocentrism in sea level rise relocation and retreat policies in the US. Global Environmental Change, 49: $10-13$.

McClain, Z., Hawkins, L. A., and Yehia, B. R. (2016). Creating welcoming spaces for lesbian, gay, bisexual, and transgender (LGBT) patients: An evaluation of the health care environment. Journal of Homosexuality, 63(3), 387-393.

McCright, A., \& Dunlap, R. (2011). Cool dudes: The denial of climate change among conservative white males in the United States, Global Environmental Change, 21(4), 1163-1172. DOI: 10.1016/j.gloenvcha.2011.06.003

McDowell, L. (1992). Doing Gender: Feminism, Feminists and Research Methods in Human Geography. Transactions of the Institute of British Geographers, 17(4): 399-416.

McLafferty, S. (2016). Conducting Questionnaire Surveys. In N. Clifford, M. Cope, T. Gillespie and S. French (Eds.), Key Methods in Geography (pp. 129-142). Sage Publications: Los Angeles.

McMichael, A. J., Butler, C. D., and Dixon, J. (2015). Climate change, food systems and population health risks in their eco-social context. Public Health, 129(10): 1361-1368.

Mitchell, D. (2011). Labor's geography: Capital, violence, guest workers and the post-World War II landscape. Antipode, 43(2), 563-595.

Misgav, C., and Johnston, L. (2014). Dirty dancing: the (non) fluid embodied geographies of a queer nightclub in Tel Aviv. Social \& Cultural Geography, 15(7), 730-746.

Mohanty, C. (1984). Under Western eyes: Feminist scholarship and colonial discourses. Boundary 2, 333-358.

Moser, S. C. (2010). Now more than ever: The need for more societally relevant research on vulnerability and adaptation to climate change. Applied Geography, 30: 464-474.

Mortreux, C., and Barnett, J. (2009). Climate change, migration and adaptation in Funafuti, Tuvalu. Global Environmental Change, 19(1), 105-112.

Myers, T. A., Nisbet, M. C., Miabach, E. W., and Leiserowitz, A. A. (2012). A public health frame arouses hopeful emotions about climate change. Climate Change, 113(3-4): 11051112.

Nabi, R. L. (2003). Exploring the framing effects of emotion: do discrete emotions differentially influence information accessibility, information seeking, and policy preference? Community Research, 30: 224-247. DOI: 10.1177/0093650202250881

Nabi, R. L., Gustafon, A., and Jensen, R. (2018). Framing climate change: exploring the role of emotion in generating advocacy behavior. Science Communication, 40(4): 442-468.

Nagar, R. (2014). Muddying the Waters: Coauthoring feminisms across scholarship and activism. University of Illinois Press.

Nama, N., MacPherson, P., Sampson, M., and McMillan, H. J. (2017). Medical students' perception of lesbian, gay, bisexual, and transgender (LGBT) discrimination in their learning environment and their self-reported comfort level for caring for LGBT patients: a survey study. Medical education online, 22(1), 1368850. 
Narayan, U. (2004). The project of feminist epistemology: Perspectives from a nonwestern feminist. The feminist standpoint theory reader: Intellectual and political controversies (pp. 213-224).

Nelson, V., Meadows, K., Cannon, T., Morton, J., and Martin, A. (2002). Uncertain Predictions, Invisible Impacts, and the Need to Mainstream Gender in Climate Change Adaptations, Gender \& Development, 10(2): 51-59.

Norgaard, K. M. (2012). Climate denial and the construction of innocence: Reproducing transnational environmental privilege in the face of climate change. Race, Gender \& Class, 19(1/2): 80-103.

Obradovich, N., Migliorini, R., Paulus, M. P., and Rahwan, I. (2018). Empirical evidence of mental health risks posed by climate change. Proceedings of the National Academy of Sciences, 115(43): 10953-10958.

Oswin, N. (2008). Critical geographies and the uses of sexuality: deconstructing queer space. Progress in Human Geography, 32(1): 89-103.

Pachauri et al. (2014). IPCC Climate Change 2014: Synthesis Report. Contribution of Working Groups I, II and III to the Fifth Assessment Report of the Intergovernmental Panel on Climate Change [Core Writing Team, R.K. Pachauri and L.A. Meyer (eds.)]. IPCC, Geneva, Switzerland, $151 \mathrm{pp}$.

Plutzer, E., McCaffrey, M., Hannah, A. L., Roseau, J., Berbeco, M., and Reid, A. (2016). Climate confusion among U.S. teachers. Science, 351(6274): 664-665. DOI: 10.1126/science.aab3907

Pretty, G., Chipuer, H. and Bramston, P. (2003). Sense of place amongst adolescents and adults in two rural Australian towns: the discriminating features of place attachment, sense of community, and place dependence in relation to place identity. Journal of Environmental Psychology, 23: 273-287.

Puar, J. (2011). 'I Would Rather Be a Cyborg Than a Goddess: Intersectionality, assemblage, and affective politics. Transversal.

Rachel Carson Council. (2021). “Our Work.” Rachel Carson Council. https://rachelcarsoncouncil.org/our-work/

Rampton, S., and Stauber, J. (2001). Trust us, we're experts! How industry manipulates science and gambles with your future. New York: Tarcher/Putnam.

Relph, E. (1976). Place and Placelessness, London: Pion.

Rodó-de-Zárate, M., and Baylina, M. (2018). Intersectionality in feminist geographies. Gender, Place \& Culture, 25(4), 547-553.

Rothrock, B. A. (2020, September 30). Hurricanes and Marginalization: How Climate Disasters Affect LGBTQ+ Persons. The Rachel Carson Council. https://rachelcarsoncouncil.org/hurricanes-and-marginalization-how-climate-disastersaffect-lgbtq-persons/

Rose, G. (1993). Feminism and Geography: The Limits of Geographical Knowledge, Polity, Cambridge.

Ryan, K., Gandha, T., Culbertson, M., and Carlson, C. (2014). Focus Group Evidence: Implications for Design and Analysis, American Journal of Evaluation, 35(3), 328-345.

Ryan, K. (2016). Incorporating emotional geography into climate change research: A case study in Londonberry, Vermont, USA. Emotion, Space and Society, 19, 5-12.

Saldana, J. (2016). The Coding Manual for Qualitative Researchers ( $3^{\text {rd }}$ Ed.). London, UK: SAGE. 
Scannell, L., and Gifford, R. (2010). Defining place attachment: A tripartite organizing framework. Journal of Environmental Psychology, 30: 1-10.

Seamon, D. (1979). A geography of the lifeworld: Movement, rest, and encounter. Croom Helm.

Shabazz, R. (2015). Spatializing Blackness: Architectures of confinement and black masculinity in Chicago. University of Illinois Press.

Sharp, J. (2009). Geography and gender: what belongs to feminist geography? Emotion, power and change. Progress in Human Geography. 33 (1): 74-80.

Sharp, J. and Dowler, L. (2011). Framing the field. In V. Del Casino Jr., M. Thomas, P. Cloke, and R. Panelli (Eds.), A companion to social geography (pp. 146-160). SAGE Publications.

Sheridan, D., Zolobczuk, J., Huynh, K., and Lee, D. L. (2017). Workplace harassment and attitudes towards LGBT people: Differences across human service occupations in South Florida. Florida public health review, 14(1), 1.

Shinn, J. E., and Caretta, M. A. (2020). 'If it Wasn't for the Faith-Based Groups, We Wouldn't Be Where We Are Today": Flooding Response and Recovery in Greenbrier County, WV. The Southeastern Geographer, 60(3), 235-253.

Schoenefeld, J. J., and McCauley, M. R. (2016). Local is not always better, the impact of climate information on values, behavior and policy support. Environmental Studies Science, 6: 724-732.

Smith, F. M. (2016). Working in Different Cultures and Different Languages. In N. Clifford, M. Cope, T. Gillespie, and S. French (Eds.), Key Methods in Geography (pp. 88-106), SAGE: Los Angeles.

Stone, A. L. (2018). The geography of research on LGBTQ life: Why sociologists should study the South, rural queers, and ordinary cities. Sociology Compass, 12(11): e12638.

Storey, D., and Hunter, S. (2010). Kiribati: an environmental 'perfect storm'. Australian geographer, 41(2), 167-181.

Stukes, P. (2014). “A Caravan of Hope-gay Christian Service: Exploring Social Vulnerability and Capacity-building of Lesbian, Gay, Bisexual, Transgender and Intersex Identified Individuals and Organizational Advocacy in Two Post Katrina Disaster Environments." $\mathrm{PhD}$, Texas Women's University.

Sultana, F. (2014). Gendering Climate Change: Geographical Insights. The Professional Geographer, 66(3): 372-381.

Taylor, L. (2016). Case Study Methodology. In N. Clifford, M. Cope, T. Gillespie and S. French (Eds.), Key Methods in Geography (pp. 581-596). SAGE: Los Angeles.

Tierney, K. (2019). Disaster: A Sociological Approach. Polity Press. Cambridge, UK.

Tschakert, P., R. Tutu, and Alcaro, A. (2013). Embodied experiences of environmental and climatic changes in landscapes of everyday life in Ghana. Emotion, Space and Society, 7: 13-25.

Tuan, Yi-Fu. (1979). Space and Place: Humanistic Perspective.

Valentine, G. (2007). Theorizing and Researching Intersectionality: A Challenge for Feminist Geography. The Professional Geographer, 59(1): 10-21.

Vazzana, Caryn M., and Jeta Rudi-Polloshka. (2019). Appalachia has got talent, but why does it flow away? A study of the determinants of brain drain from rural USA. Economic

Development Quarterly, 33(3): 220-233.

Walker, A. [1979] 2003. Coming apart: In L. Phillips (Ed.), The Womanist Reader, 3-11. 
Walters, S. D. (1996). From here to queer: Radical feminism, postmodernism, and the lesbian menace (or, why can't woman be more like a fag?). Sign: Journals of Women in Culture and Society, 21(4), 830-869.

Watson, A., and Till, K. E. (2010). Ethnography and participant observation. The SAGE Handbook of Qualitative Geography, 121-137.

Willox, A. C., Harper, S. L., Ford, J. D., Landman, K., Houle, K., Edge, V., and the Rigolet Inuit Community Government. (2012). "From this place and of this place:" Climate change, sense of place, and health in Nunatsiavut, Canada, Social Science \& Medicine, 75: 538547

Wimark, T. (2019). Sexuality and emotions situated in time and space. In Stodulka T., Dinkelaker S., and F. Thajib. (Eds.), Affective Dimensions of Fieldwork and Ethnography. Theory and History in the Human and Social Sciences (pp. 157-166). Springer, Cham. https://doi.org/10.1007/978-3-030-20831-8_14

Wimark, T. (2020). Life course approaches. International Encyclopedia of Geography, 179-183.

Wisner, B., Berger, G., and Gaillard, J.C. (2017). We've seen the future, and it's very diverse: Beyond gender and disaster in West Hollywood, California. Gender, Place and Culture, 24(1): 27-36.

Worth, N. (2009). Understanding youth transition as 'becoming': identity, time and futurity. Geoforum, 40: 1050-1060.

Wright, M. (2010). Gender and geography II: bridging the gap - feminist, queer, and the geographical imaginary. Progress in Human Geography, 34(1): 56-66.

Yamashita, A., Gomez, C., \& Dombroski, K. (2017). Segregation, exclusion, and LGBT people in disaster impacted areas: experiences from the Higashinihon Dia Shinsai (Great EastJapan Disaster). Gender, Place \& Culture, 24(1): 64-71.

Yuval-Davis, N. (2006). Intersectionality and Feminist Politics. European Journal of Women's Studies, 13(3): 193-209. 